Portland State University

PDXScholar

\title{
Components Integral to the Consumer's Decision- Making Process Regarding the Regional Shopping Centers of Portland, Oregon
}

James A. Swanson

Portland State University

Follow this and additional works at: https://pdxscholar.library.pdx.edu/open_access_etds

Part of the Geography Commons, and the Social and Cultural Anthropology Commons Let us know how access to this document benefits you.

\section{Recommended Citation}

Swanson, James A., "Components Integral to the Consumer's Decision-Making Process Regarding the Regional Shopping Centers of Portland, Oregon" (1980). Dissertations and Theses. Paper 2976.

https://doi.org/10.15760/etd.2971

This Thesis is brought to you for free and open access. It has been accepted for inclusion in Dissertations and Theses by an authorized administrator of PDXScholar. Please contact us if we can make this document more accessible: pdxscholar@pdx.edu. 
AN ABSTRACT OF THE THESIS OF James A. Swanson for the Master of Science in Geography presented February 20, 1980.

Title: Components Integral to the Consumer's Decision-Making Process Regarding the Regional Shopping Centers of Portland, Oregon

APPROVED BY MEMBERS OF THE THESIS COMMITTEE:

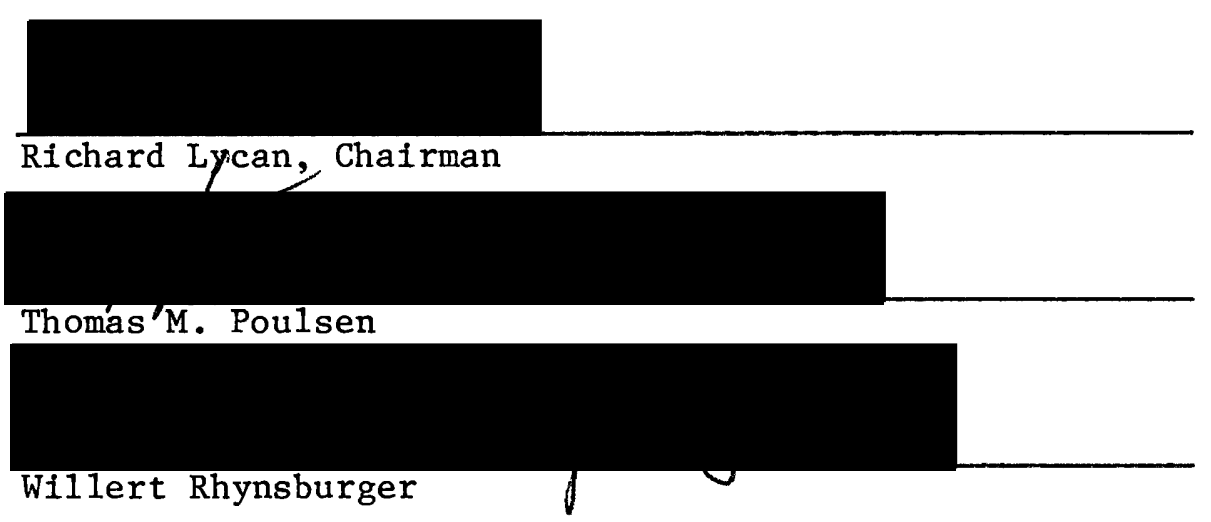

The research problem that the thesis is concerned with is the definition of the components of the "attractiveness" of a regional shopping center as they pertain to the decision-making process of the consumer. In addition, variations among the shopping patterns of male and female shoppers and among income groups are examined.

Two hypotheses are tested. The first hypothesis states that the physical characteristics of a regional shopping center are important components in the consumer's decision when selecting a particular center. The second hypothesis states that significant variations exist between the shopping patterns of male and female consumers and between income 
groups with respect to the number of centers utilized and the frequency of shopping at Portland's regional shopping centers.

In order to test these hypotheses, data was gathered by utilizing a self-administered. questionnaire. The sample was drawn from various classes of Portland Community College. Since Portland Community College offers a community education program throughout the Portland area at various elementary and secondary schools, the sample of classes provided a good geographic coverage of the Portland area. The data gathered by the questionnaire concerned various elements important to the decisionmaking process, consumer shopping patterns as they pertain to Portland's regional shopping centers and the demographic characteristics of the sample population.

To delineate the components important in the consumer's decision-making process, the data was subjected to a factor analysis. Cross-tabulations were used to distinguish the shopping patterns of male and female shoppers and various income groups.

Analysis of the data supports the first hypothesis. Three factors were isolated by the factor analysis which define the components most important in the consumer's decision to shop at a particular regional shopping center. These components are quality of service, the physical characteristics of the center (i.e., new, modern, covered, enclosed, etc.), and consumer, comfort when shopping (i.e., clean, quiet, dry, etc.) 
The second hypothesis that variations exist among the shopping patterns of male and female consumers and among income groups with respect to Portland's regional shopping centers is not wholly supported. Analysis indicates that female shoppers utilized more regional shopping centers than do male shoppers. However, with respect to the frequency of shopping at a regional center, there is no significant difference between male and female shoppers.

Variations among the shopping patterns of income groups indicate that as income increases there is a corresponding increase in the frequency of shopping at a regional shopping center. However, there are no distinct differences regarding the number of centers utilized among the various income groups. 
ÇOMPONENTS INTEGRAL TO THE CONSUMER'S DECISION-MAKING PROCESS REGARDING THE REGIONAL SHOPPING CENTERS

OF PORTLAND, OREGON

by

JAMES A. SWANSON

A thesis submitted in partial fulfillment of the requirements for the degree of

\author{
MASTER OF SCIENCE \\ in \\ GEOGRAPHY
}

Portland State University 
TO THE OFFICE OF GRADUATE STUDIES AND RESEARCH:

The members of the Committee approve the thesis of James A. Swanson presented Apri1 2, 1980.

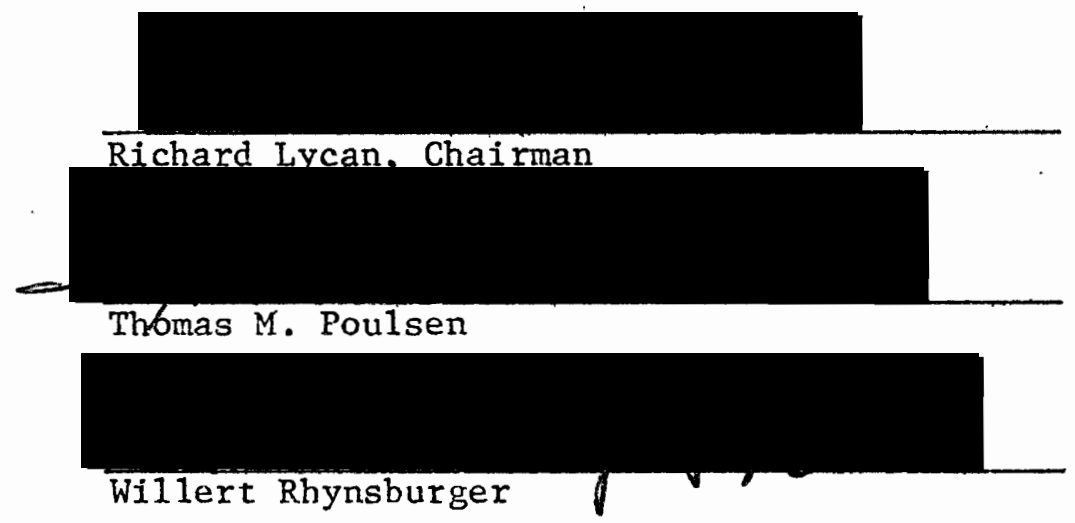

APPROVED :

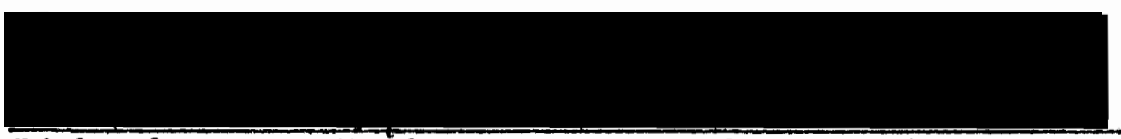

Richard Lycan, Head, Department of Geography

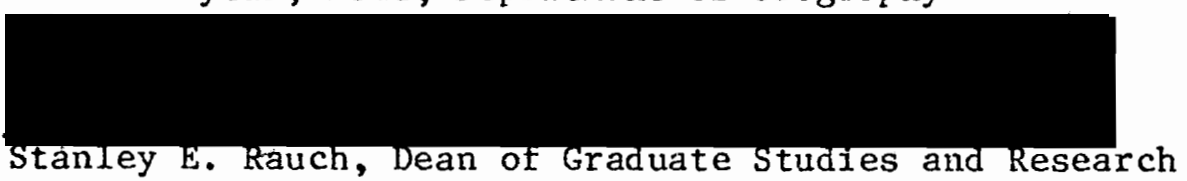


TABLE OF CONTENTS

PAGE

LIST OF TABLES . . . . . . . . . . . . . . . . . . . • IV

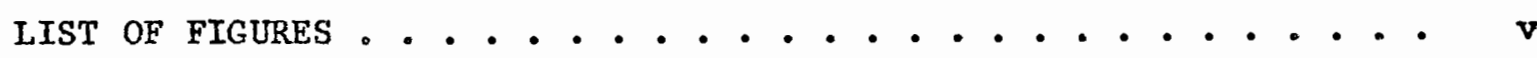
CHAPTER

I INTRODUCTION . . . . . . . . . . . . . . . . . 1

II LITERATURE REVIEW . . . . . . . . . . . . . . . . . 5

Central Place Theory . . . . . . . . . . . 5

The Gravity Model ....... . . . . . . . 9

Consumer Behavior . . . . . . . . . . . 17

Conclusion .. . . . . . . . . . . . 25

III METHODOLOGY •. . . . . . . . . . . . . . . . 27

Hypotheses . . . . . . . . . . . . . 27

Delineation of Portland's Regional Shopping Centers 29

The Survey . . . . . . . . . . . . . 34

Data Analysis: Methodology ... . . . . . . . 41

Conclusion ................... 42

IV ANALYSIS . . . . . . . . . . . . . . . . . . 44

Conclusion . . . . . . . . . . . . . 71

v DISCUSSION • . . . . . . . . . . . . . . . 75

SELECTED REFERENCES ... . . . . . . . . . . . . . . . . . 80

APPENDIX A . . . . . . . . . . . . . . . . . . . . . . 89

APPENDIX B . . . . . . . . . . . . . . . . . . . . . 91 
LIST OF TABLES

TABLE

I Portland's Regional Shopping Centers . . . . . . . . . . 31

II Normal Rotated Factor Matrix . . . . . . . . . . . 45

III Utilization of Portland's Regional Shopping Centers . . . . 47

IV Factor Score Index . . . . . . . . . . . . . . . 49

V Relative Drawing Power . . . . . . . . . . . . 50

VI Second Choice Center Among Lloyd Center Shoppers . . . . . 56

VII Second Choice Center Among C.B.D. Shoppers . . . . . . . 58

VII Second Choice Center Among Washington Square Shoppers . • 60

IX Point of Origin of Shopping Trip . . . . . . . . . . . 62

X Mode of Transportation for Shopping Trip . . . . . . . . 63

XI Appeal of Type of Design in the Consumer's Decision ... . . 64

XII Appeal of the Center's Age in the Consumer's Decision . . . 65

XIII Appeal of an Open or Enclosed Shopping Area . . . . . . . 65

XIV Number of Centers Utilized by Sex . . . . . . . . . . 66

XV Frequency of Shopping by Sex . . . . . . . . . . . . 67

XVI Use of Centers for Other Than Shopping . . . . . . . . . 67

XVII Number of Centers Shopped by Income . . . . . . . . . . 68

XVIII Frequency of Shopping by Income . . . . . . . . . . 69

IXX Distribution of Income by Age Groups . . . . .... . . . 70

XX Frequency of Shopping Among Female and Male Income Groups. . 72 
LIST OF FIGURES

FIGURE

PAGE

1. Regional Shopping Centers: Portland, Oregon . . . . . 33

2. Distribution of Respondents . . . . . . . . . . . 37

3. Portland Community College Sampling Sites . . . . . . 38

4. Lloyd Center Primary Shoppers . . . . . . . . . . 52

5. Washington Square Primary Shoppers . . . . . . . . . 53

6. C.B.D. Primary Shoppers . . . . . . . . . . . 54

7. Second Choice Centers of Lloyd Center Shoppers . . . . . 57

8. Second Choice Centers of C.B.D. Shoppers . . . . . . . 59

9. Second Choice Centers of Washington Square Shoppers . . . 61 
CHAPTER I

\section{INTRODUCTION}

Recently, many geographers have adopted a behavioral approach for depicting the processes involved in the discretionary spatial choice of consumers. This approach focuses on consumer shopping decisions made considering a number of alternatives, while weighing the relative importance of factors involved in the decision-making process. Accompanying the behavioral approach is a re-examination of classical central place theory and gravity models in which distance minimization and retail center size play important roles.

This study focuses on the elements of a regional shopping center that comprise its "attractiveness". Attractiveness is considered to be an important elenent when the consumer selects a regional shopping center. Elements of attractiveness can be incorporated into a locational model; a gravity model could provide a better predictive tool than similar models based simply upon center size and distance.

Central place theory provides an explanation of the location, sire, nature, and spacing of clusters of retail and service activities in space. Central place theory has been applied to the urban environment in a nanner that shows a hierarchical organization of retail centers and predicts their structure and distribution in space.

Retail market areas have usually been delineated through the utilization of gravity models. A major limitation of gravity models, however, is that although they describe consumer spatial behavior 
patterns in space, they are devoid of an explicit underlying theoretical base. Explicit within the body of central place theory and implicit in the utilization of the gravity model is the assumption of the economic man. The consumer is depicted as a rational human being who minimizes the costs of a shopping trip by patronizing the closest shopping center offering the desired goods.

Consequently, behavioral geographers criticised the rational economic man approach as an avenue which limits the level of explanation. Behavioral geographers have argued that variations in consumer shopping patterns from those predicted by normative theory can be attributed to the consumer's subjective perceptions of an objective retail landscape. These perceptions represent the consumer's image of his enviornment or at least of selected attributes of the perceived environment. They influence the spatial shopping patterns of the consumer and may help to explain the "irrational" patterns that normative models, such as central place, cannot explain. However, the $k$ image that a consumer has of a retail establishment is directly ${ }^{+}$ influenced by the type of shopping trip or the good desired.

The objective retail structure of the urban environment and the behavioral processes of the consumer interact to produce the shopping $x$ patterns of the consumer. Therefore, consumer behavior is directly* related to the retail structure of the city. It is constrained by that , objective retail structure because only one set of retail opportuntties exists for any shopping trip (Clark, 1972, p. 171). When the consumer wants a convenience good, the set of retail opportunities from which to make a purchase may be quite large due to the prevalence of convenience goods stores in urban areas. When the consumer requires a higher order 
good, the opportunity set is diminished because the availability of alternative shopping opportunities varies inversely with the order of the good. Therefore, the image attached to particular stores or centers varies depending on which level of store or center is being considered. The image of a discount store is different from that of a department store (Singson, 1975). Similarly, the image of a regional shopping center should be different from that of a community shopping center: Variations in image could be due to the different components of the image of the centers or stores, or could be reflected by the same components but with different weightings depicting the amount of variation accounted for by each component. If either of these hypotheses hold, shopping trips associated with different retail establishments or centers would be influenced by the different perceptions that the consumer has of those particular elements (Engle, Kollat and Blackwe11, 1973, p. 443)

It is important to examine the retail centers of the urban spatial structure separately. Regional shopping centers should be examined separately from lower order centers when studying consumer behavior. The consumer behaves differently when choosing a regional shopping center than when choosing a community or neighborhood shopping center. This study examines consumer choice of regional shopping centers of the Port1and, Oregon area.

To determine the important, factors in the consumer's decision to shop at a specific regional shopping center, a survey was conducted utilizing a questionnaire. The data was subjected to a factor analysis technique to group those components important to the decision-making process. Cross tabulations of data were also made to examine variations 
in the shopping patterns of male and fenale shoppers, and various income groups.

Chapter II of the study presents a review of central place theory, its application to an urban hierarchy of shopping centers, and its assumptions concerning consumer behavior. The gravity model and its application as a tool for measuring trade areas are reviewed. Geographical and marketing research on the relationship of socio-economic variables and shopping patterns, and the development of retail image are also examined in this chapter.

Chapter III puts forth three hypotheses regarding the pertinent decision-making components, variations between male and female consumers, and differences in income groups with respect to regional shopping centers. This chapter also defines the regional shopping centers used in this study. It introduces the data collection and data analysis techniques that were utilized.

Chapter IV presents the decision-making components that were isolated by the factor analysis. These components were validated through an examination of actual shopping patterns associated with Portland's regional shopping centers. An analysis of variations between male and female shoppers and between. income groups is also presented. Chapter V discusses the results of this study, applies it to existing theory, and suggest possible areas of future research. 


\section{LITERATURE REVIEW}

\section{Central Place Theory}

Christaller's central place theory has served as the basis of numerous geographical studies examining the distribution of retail activities in space and the factors affecting these distributions (Berry, Barnum, and Tennant, 1962; Berry and Garrison, 1958 (a), Berry, 1967; Berry and Garrison, 1958(b); Murdie, 1965; Dacey, 1965; Clark, 1968). Christaller presented a hierarchy of urban centers characterized by their central functions, population size, and market areas. The centers occupying the lowest levels of the hierarchy, centers of least importance and size, exist in large numbers in space. Centers of greater importance and size decrease in number until the highest order centers occur very infrequently in space (Christaller, 1966). Eventually a long run equilibrium is established when there are neither too many or too few central places and no area is left unsupplied (Christaller, 1966, P. 63-88; Berry, 1967, p. 62-65).

A primary assumption of Christaller's was that of an "economic man". Christaller realized that consumers behave differently, arguing that behavioral patterns could be explained by socio-economic differences, cuitural variations, and political and natural boundaries (Christaller, 1966, p. 32-34, 45-47, 50-52). In his theory, however, the behavior of a consumer is that of the rational economic man characterized by three interrelated components: 
1) The consumer minimizes the cost of acquiring a good by shopping at the closest center offering the desired item.

2) The consumer has perfect knowledge and knows all of the centers offering the good.

3) The consumer has the perfect ability to use the knowledge, so he makes the right decision.

With these assumptions, variations in consumer behavior were explained. The consumer shops at the closest available center thereby minimizing the costs of travel. This is the least effort syndrome, that has frequently been utilized so the actions of the economic man may be explained with perfect surety (Wolpert, 1964. Pred, 1967, p.1-21. 01sson and Gale, 1968, p.229).

Central place theory was utilized to establish a hierarchy of shopping centers in the urban environment (Berry and Garrison, 1958(b). Berry, 1963. Simmons, 1964. Garner, 1966. Davies, 1972). Berry and Garrison argued that within the urban environment, there exists a hierarchical structure directly related to the hierarchy of central place theory.

Two primary factors explain this hierarchy according to Berry. First, commercial functions require different conditions of entry and thus demand minimum trade areas of different sizes for their economic success, the threshold concept:. Secondly, consumers spend different portions of their income on different goods and services, with differing degrees of frequency. Consequently, low threshold, high frequency functions are located in lower level centers. High threshold, low frequency functions are found in high level centers supplying larger trade areas. Berry concludes, "...that the hierarchical nature of 
intraurban retail structure may be attributed to the same processes that generates systems of central places." (Berry, 1963).

An interrelationship exists between consumer shopping patterns and the distribution and tenant mix of retail centers. The spatial distribution of retail centers is a reflection of consumer shopping patterns, but these patterns are likerrise influenced by the retail structure, because only a limited set of retail opportunities exist (Nystuen, 1967, p. 54. Curry, 1967, p. 218). Changes in retail patterns result from altered socio-econonic and demographic characteristics of the population, changing population distrubitions in space, and technological innovations.

For example, the increased mobility of the consumer and the suburbanization process brought about by the automobile gave rise to the suburban shopping center and the supermarket (Casparis, 1967. Vance, 1962). Suburban shopping centers and supermarket incorporated such assets as free parking and the convenience of one-stop shopping, thereby attracting the mobile consumer which resulted in the demise of the mom and pop grocery store (Nystuen, 1967).

A major component of the new retail environment was the planned regional shopping center, located primarily in suburban areas. Through time, these retail centers enhanced their positions as intervening opportunities by duplicating the retail functions of the C.B.D. (central business district) and eventually become major competitors to the C.B.D. The incorporation of new technological innovations in these centers and the increase of downtown trarfic and parking problems contributed to the decline of the C.B.D. as the major outlet of shopping goods. (Guest and Cluett, 1973. Guest, 1973. Bucklin, 1972. Cohen, 1972. Mulvihill and 
Mulvihil1, 1970. Scott, 1970. Casparis, 1969. Applebaum and Cohen, 1961).

The importance of a shopping center's trade area on it structure (i.e., tenant mix) has been studied extensively (Applebaum and Cohen, 1961. Casparis, 1967. Garner, 1966. Simmons, 1964. Berry, 1963). The demographic characteristics of the population (for example age, race, income, education and occupation) reflect the amount of disposable income and the tastes of the consumers residing within a center's trade area and influence the tenant mix of the shopping center. The interrelationship of a trade area composed primarily of one ethnic group and its retail structure is particularly striking (Pred, 1967. Suttles, 1970).

The size of a shopping center's trade area is related to the size of the shopping center. Higher order centers, the regional shopping $\sigma$ center, are characterized by large trade areas in terms of a trade area's population and spatial extent, whereas the trade areas of lower 4 level centers require less population and are more constricted spatially * (Nader and Thorpe, 1967). Central place theory results in a system of trade areas with definite boundaries denarcating spatial limits within which the shopping center has an absolute advantage in attracting consumers.

However, studies have shown this system of trade areas is an idealized situation, based on the economic man assumption rather than of * real world patterns. As Bucklin stated, "A trading area seldom, if ever, comes to a precipitous halt at contact with competing centers of influence. Instead, there is a sharing of patronage which creates an $\chi$ area of overlap between stores." (Bucklin, 1971(a), p. 30). High popu- 
lation densities in the urban environnent make it possible for retail establishments to maintain acceptable sales levels within a smaller area than that characterized by the maximum distance a consumer is willing to travel. This results in a duplication of retail facilities, thus pro-ducing extensive trade area overlap (Simon, 1973-74). Complicating this phenomena are the irrational actions of the consumer who does not shop at the closest opportunity. $\alpha$

\section{The Gravity Model}

Vaxious methods have been utilized for the measurenent or trade areas in the urban environment, utilizing such factors as population characteristics, competing facilities, and accessibility (Applebaum and Cohen, 1961, Applebaum, 1968. Getis, 1963. Rudelius Ha11, and Kerin, 1972). However, the common method utilized to measure a trade area has been the gravity model (Simon, 1973, p.68).

William Reilly pioneered the use of gravity models when he applied one to delineate the trade area of two competing cities. While the law of retail gravitation, as developed by Reilly, was intended to be utilized to delimit large trading areas, it has been considered to be applicable to highly urbanized areas (Wagner, 1974, p.32).

The basis of Reilly's model is that two cities attract trade from an intervening area in proportion to the population of both cities and in inverse proportion to the square of the distances from the two torns to any point in the intervening area (Reilly, 1931, p.9). This relationship is represented by the formula:

$$
T_{A} / T_{B}=\left(P_{A} / P_{B}\right)\left(D_{B} / D_{A}\right)^{2}
$$


where: $T_{A}$ and $T_{B}$ represent the ratio of the trade from the intermediate location attracted by centers $A$ and $B$. $P_{A}$ and $P_{B}$ are the population of cities $A$ and $B$. $D_{A}$ and $D_{B}$ represent the respective distance of cities $A$ and $B$ from the intermediate location.

The breaking point concept indicates the point at which neither of the two cities has an advantage, with the numberical probability of 0.5 .

$$
\mathrm{Bb}=\frac{\mathrm{D}_{\mathrm{ab}}}{1+\sqrt{\frac{\mathrm{P}_{\mathrm{a}}}{\mathrm{P}_{\mathrm{b}}}}}
$$

where: $B_{b}$ is the breaking point between city $A$ and city $B$. $D_{a b}$ is the distance between cities $A$ and $B$. $P_{b}$ is the population of city $B$. $\mathrm{P}_{\mathrm{a}}$ is the population of city A.

The economic man is an implicit assumption within Reilly's law of retail gravitation. Up to a certain distance, the consumer travels to the closest city for his shopping needs, the least effort maximization of utility syndrome. The consumer is also required to know all available retail opportunities and have the ability to make the correct choice.

$\alpha$ The next major step in utilizing the form of the gravity model was accomplished by Huff. Realizing that the consumer is not the rational consumer of the economic man assumption, Huff contended that variations in consumer shopping patterns are attributable to numerous socio- $\alpha$ economic characteristics of the consumer and the structure of the retail environment (Huff, 1959(a), 1959(b)). Huff developed a gravity model based on Luce's "basic choice axiom", presented by the formula: 
$P_{T}(X)=V(X) / \sum_{Y \in T}$

where: $P_{T}(X)$ is the probability of an individual choosing.

alternative

$X$ from a finite set of $T$ alternatives.

$T$ is the subset of some universal set $U$, and

$\mathrm{V}(\mathrm{X})$ is a positive real valued function $\mathrm{V}$ on $\mathrm{T}$.

The basic proposition of this axiom is that consumer choice is but viewed as a probabilistic phenomenon. The consumer is assumed to be able to evaluate the elements of a universal set $U$, along some comparative dimension, and select a finite set of $\mathrm{T}$ alternatives (Huff and BatselI, 1975, p.165).

Based on this axiom, Huff's model described the behavior of a consumer as a probabilistic phenomenon that can be ascertained by the consumer's perceived utility of alternative shopping centers.

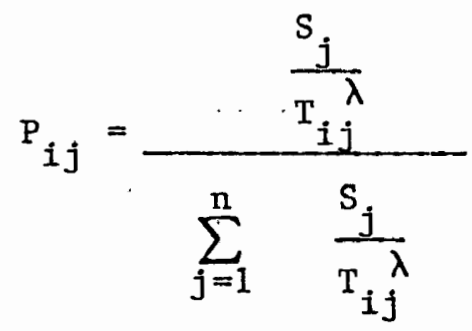

where: $P_{i j}$ is the probability of a consumer located at point $i$ shopping at center $j$ :

$S_{j}$ is the size of shopping center $j$.

$T_{i j}$ is the travel time from $i$ to $j$ :

$\lambda$ is the parameter which when calculated empirically reflects the effect of driving time on various types of shopping trips.

The probability of a consumer choosing a particular center is equal to the ratio of the perceived utility of that center to the 
combined utility of all centers in the subset of competing centers of which $j$ is a member. The collection of shopping centers comprising the subset is a function of the type of shopping trip which the consumer is considering, because some goods can be acquired only from certain types of centers.

An explicit element of the model is the exponential type function of travel time or "economic distance". This numerical value, while based on empirical evidence, represents the willingness of consumers to travel various distances for certain types of goods or services. Huff argues that value differences among goods are based on four variables;

1) the degree of substitutability of various products;

2) expected absolute price differential between different products (the consumer is willing to travel farther if a low purchase price results in net savings);

3) the absolute price of a product in relation to a consumer's income (when the price of a good is quite high in relation to the consumer's income, the consumer is willing to travel farther to take advantage of a wider selection of goods); and 4) the degree of "psychic income" anticipated from different products (the consumer's evaluation of the anount of satisfaction acquired from the purchase of a good will influence his willingness to trave1) (Huff, 1962, p.20-21).

Criticisms abound, however, when the gravity model is applied to the intra-urban situation, particularly with regard to the variable of distance. It is generally argued that the variable of distance is not $\chi$ uniform in its influence on interaction, in this case the shopping 
patterns of the consumer (Isard, 1960, p.512-515. Lee, 1973, p.59-60). Bucklin contends that the factor of distance loses much of its value in the urban area as it is easier to predict the behavior of a consumer between two cities twenty miles apart than it is to predict the behavior of a consumer situated between shopping centers two miles apart. The $f$ marginal distance is much less in the urban environment and the constraint of travel time is not always as powerful (Bucklin, 1971 (b), p. 492-493).

By eliminating the idea of using mass as a surrogate variable and replacing it with a composite attractiveness index, Huff attempted to vary the effects of distance with the attractiveness of a shopping center.

$$
P_{i j \cdot}=A_{j} D_{i j} / \sum_{j=1}^{n} A_{j}^{\alpha} D_{i j}^{\lambda}
$$

where: $A_{i j}$ is the attraction index of retail facility $j$.

$D_{i j}$ is the accessibility of retail facility $j$ to a consumer located at $i$.

$\alpha \lambda$ empirically determined parameters.

Huff realized that the perceived utility of a shopping center is composed of numerous factors for which the attraction index represents the composite variable. A major problem with the utilization of these factors is estimating the parameters of each variable. However, if the two variable models were expanded to a $q$ variable model, utilizing the least squares technique for parameter estimation, it would be improved by eliminating the ceteris paribus assumptions characteristics of the two variable model (01sson and Gale, 1968, p.237). In this instance 
Huff presents a model depicting the effects of price, distance, and size on consumer spatial behavior and subsequently on the spatial extent of the trade area (Huff, 1975):

$$
\operatorname{Pij}_{i j}=\frac{s_{i j}^{\gamma_{s}} \cdot D_{i j}^{\gamma_{d}} \cdot L_{i j}^{\gamma_{1}}}{\sum_{j=1}^{n} s_{i j}^{\gamma_{s}} \cdot D_{i j}^{\gamma_{d}} \cdot L_{i j}^{\gamma_{1}}}
$$

where: $P_{i j}$ is the probability of a consumer from area $i$ journeying to location $j$ :

$S_{i j}$ the square footage of selling space in the retail location.

$\boldsymbol{\gamma}_{\mathrm{s}}$ the sensitivity of $\mathrm{P}_{i j}$ with respect to store size. $D_{i j}$ distance between $i$ and $j$.

$\boldsymbol{\gamma}_{\mathrm{d}}$ sensitivity of $\mathrm{P}_{i j}$ to distance.

$L_{i j}$ the price level for a consumer at $i$ with respect to location $j$.

$Y_{1}$ the sensitivity of $P_{i j}$ with respect to price.

Whether or not the predictability of the model would be significantly increased by a $q$ variable model is unknown. Probably the greatest benefit that could be obtained from such a model would result from an analysis of the attraction index and its influence on various shopping patterns. This would produce a greater understanding of major factors influencing the shopping patterns of the consumer in the intraurban environment.

The gravity model has been a useful tool for the delineation of the market areas of shopping centers. It also is a tool for predicting the 
potential. success of a retall center in specific location, when using the demand and disposable income of the population and competing facilities in conjunction with the size and distance components of the gravity model (Lakshmanan and Hansen, 1965).

Simon contends, however, that its effectiveness stems from the adjustment of the distance exponent to the data being analyzed (Simonș, 1973-74, p. 74). The question then arises as to whether the parameters are part of the variable of distance or are not specifically related to distance. Simon argues that distance operates as an error term of sorts for all other variables in the equation to maximize a goodness of fit. The basis of this problem. is the absence of an underlying theory to the gravity model explaining the values attached to distance or for that matter to the values of any of the other variables.

The gravity model used as a tool for the prediction of interaction between areas or points in space is what Huff refers to as an empirical device that explains nothing about why certain observed regularities occur. The model is not a basic law or theory explaining human behavior or human interaction.

While a number of attempts have been made to supply the gravity model with a theoretical base (Neidercorn and Bechdo1t, 1969̣. Smith, 1975. Tsard, 1975.) none have produced cogent and conclusive arguments.

An important variation of the gravity model espoused by a number of authors is the spatial choice model incorporating alternative shopping centers or retail outlets in the decision-making process (Lakshmanan and Hansen, 1965. Burnett, 1973. Ewing, 1974. Hilliard, Vaughn and Reynolds, 1975). The basis of the spatial choice model is 
that consumer movements in space are deternined by a choice among alternative shopping opportunities. The probability of interaction with a center is defined by its distance from an origin point compared to the distance to other centers. The model developed by Hilliard, Vaughn and Reynolds, perceives the utility of a center to be affected by its location relative to another center. The model allows for the interaction between centers to affect the determination of consumer probabilities of shopping center choice:

$$
U_{j}=\left[I_{j}+\sum_{i=j-j} I_{j} / D_{i j}^{\lambda}\right]^{2} / D_{j}^{1}
$$

where: $D_{i j}$ is the perceived cost of travel between center $i$ and j:

$D_{j}$ is the perceivel cost of travel from origin $i$ to site j.

$\left[I_{j}+I_{i} / D_{i j}^{\lambda_{2}}\right]$ is the net drawing power of center $j$. This type of model is more. realistic, as it allows for cases where consumer perceptions of the utility of a shopping center are not assumed to be independent of other centers. However, one problem with the spatial choce model is that estimation of parameters has proven to be complicated, and in some instances unfeasible, when the set of variables increases beyond a relatively small number (Ewing, 1974, p.86).

The gravity model or the spatial choice model deals with consumer behavior. Thus, an explicit understanding of the factors affecting consumer choice is required. Huff points out that one of the areas of needed research in consumer spatial behavior is concerned with the determination of (1) the perceived attributes, as well as (2) the objective equivalents that specify the utility of various retail establishments to a consumer (Huff, 1975, p.171). 
Consumer Behavior

Geographers have come to the conclusion that the consumer is not the rational economic man, but instead is a free consumer whose actions in space are more accurately attributed to a subjective interpretation of an objective landscape (Stea and Downs, 1970, p.4-5). The assumption that the consumer will patronize the nearest center is regarded as merely a theoretical notion intended to simplify the formulation of abstract concepts (01sson and Gale, 1968, p.218). This assumption is not necessarily characteristic of all consumer behavior, particularly in the urban environment. Thompson contends, "...if one is to attempt to link |his model to consuner behavior, he should first study the manner in which the objective landscape is subjectively interpreted by the consumer, and then and only then, attempt to develop a model designed to capture effectively the results of free consumer choice." (Thompson, 1966, p.8-9).

Rushton states that a useful postulate of spatial behavior describes the procedure by which alternative locations are evaluated and subsequent choices are made. He refers to this procedure as spatial behavior, as opposed to behavior in space, which is merely the actual spatial choices made within a system and is therefore dependent on the particular spatial system in which it occurs (Rushton, 1969(a), p.392). Attempts to develop these postulates have ranged from studies of action space and learning theory to empirical studies examining various elements of the retail structure (such as the price of goods, quality of merchandise, selection, and distance), and their effects on the decisionmaking process of various socio-economic and demographic consumer groups. 
The concept of action space concerns the objective retail structure of the city, the location of the household in relation to the actual location of all potentail urban activities, the objective levels of center attractiveness, and the subjective utility or preference that an individual associates with them (Horton and Reynolds, 1971, 1975; Chapin, 1968). The subjective utility or preference is evaluated with respect to potential and actual travel behavior.

As an individual acquires and assimilates information on the objective spatial structure of the city, his action space is formed. The action space of an individual is affected by a number of variables exogenous to the spatial system. These variables influence the accumulocation and interpretation of pertinent information of the objective environment, thereby producing distinctive biases in spatial perceptions and choices. Variations in behavior may be accounted for by such socioeconomic and demographic variables as sex, race, social status, income, occupation, and education, a11 of which influence variations in the action space of different persons.

However, the theory of action space does not attribute variations in behavior solely to socloeconomic and demographic variables. It also recognizes the influence of time and change in the spatial system of the city. Changes through time in the retail structure of the city produce corresponiing changes in the spatial behavior of the consumer as alternative locations become available and past retail opportunities are altered. Consequently the consumer is involved in an endless learning process due to continual change in the retail environment of the city. Changes in consumer perceptions and behavior may also be attributable to changes in consumer spatial preference whereby the same opportunities 
are evaluated differently (Rushton, 1969. Pred, 1967, p. 14).

Learning theories have traditionally contended that changes in the spatial behavior of the consumer are attributable to changes in their evaluations and perceptions of alternative shopping opportunities. The consumer must resolve which center or unit to visit to purchase a specific good or set of goods. The new consumer must initiate a pattern of spatial search behavior through which particular retail needs are satisfied. The consumer will test a number of possible combinations of markets (Golledge's "marketing strategies") and from their shopping experiences they will decide which provide the greatest rewards as satisfactory responses are retained and unsatisfactory, responses are rejected (Golledge and Brown; 1967, p. 116-117).

However, as Hudson and others have noted, these search patterns vary according to the social, psychological, and economic attributes of the consumer as well as the time, location, and retail structure in which the consumer is shopping (Hudson, 1975, p. 143. Engle, Kollat and Blackwe11, 1973, p. 392. Horton and Reynolds, 1971, p. 37-38. Lathrop, 1971, p. 234. Bucklin, $1967(\mathrm{~b})$, p. 41-42). Hudson found that factors of uncertainty and distance affect spatial behavior. The trade-off between uncertainty and distance is different for search patterns involving individual stores and those involving shopping centers. The factors of distance and uncextainty reduction are incompatible at the store level, as accessibility is most important, while they are compatible at the shopping center level (Hudson, 1975, p. 153).

Eventually the consumer will reach a point of recurrent shopping patterns, indicative of a spatial equilibrium between consuner perceptions and satisfaction with current retail choices and their locations. 
The consumer will then exhibit habitual responses which may include the patronage of one or more centers (Golledge and Brown, 1967. Golledge, 1970. Horton and Reynolds, 1971. Burnett, 1973). Golledge presents some conceptual learning models that could be applicable to geographical problems (Golledge, 1969), and both Golledge and Burnett, in two separate articles, portray the operationalization of learning models (Golledge, 1967. Burnett, 1973).

The contention that variations in consumer behavior can be attributed to socio-economic variables has led to numerous empirical studies. The traditional variables studied are age, race, income and socioeconomic or social status.

Studies concerning the variation in the behavior of income groups have found that the upper income groups are willing to travel farther to purchase a good or set of goods because of their ability to absorb the additional costs of travel (Friedly, 1965. Davies, 1969. Bucklin, 1967. Prasad, 1972. Nader, 1969). The willingness of upper income groups to absorb the additional costs have been hypothesized to be a function of the greater demand for a larger selection of goods among the higher income groups (Friedly, 1965. Davies, 1969). The higher incidence of multiple car ownership within higher income groups has given them a mobility advantage over the lower income consumer (Holly and Wheeler, 1972).

Studies examining the influence of race have found that the black consumer generally shops in the C.B.D., while the white consumer tends to patronize suburban shopping centers. (Cox and Stafford, 1972. Bucklin, 1967 (b) Sexton, 1972.). The locational proximity of the C.B.D. to black resirlential areas, a feeling of security anong blacks shopping in the 
C.B.D., and the funneling of public transportation systems through the downtown area are major factors contributing to the differences between the black and white shopper (Cox and Stafford, 1972). However, it was discovered that as household income increases the proportion of blacks shopping in the C.B.D. decreases while shopping in the suburban centers increases (Cox and Stafford, 1972. Sexton, 1972).

Age has very little to do with variations in the shopping patterns and behavior of the consumer. Studies have indicated that significant variations in the behavior of age groups are primarily between the aged, sixty-five and older, and the other age gxoups (Jonassen, 1955. Davies, 1969). The aged consumer is reluctant to change his shopping habits, while the younger consumer exhibits a greater propensity to alter his/ her shopping patterns when alternative retail opportunities become available. The aged consumer is less mobile, tending to be handicapped by the inability to drive, high insurance rates, prohibitive costs of taxis, and unsuitability of public transportation (Sherman and Britton, 1973).

Occupation, education, income, and in some instances, ethnic background are combined to produce an index of social status (Horton and Wagner, 1969). Studies have shown that the high and middle class groups are much more mobile than the lower status consumers (Scott, 1970. Buck1in, 1967. Jonassen, 1955. Horton and Wagner, 1959. Lathrop, 1971). The shopping patterns of these two groups are, therefore, different. However, studies have indicated that social status is not as influential in shopping behavior today as in past years due to the suburbanization process and the rising levels of income and the attain- 
ment of educational goals among the blue collar workers (Rich and Jain, $1968, \mathrm{p} .4(-48)$

Other studies have produced findings contradicting the influence of socio-economic variables on consumer behavior. Mason and Moore found that socio-economic variables did not satisfactorily explain the variations in patterns of shopping trips to Birmingham, Alabana among groups of consumers residing outside of the metropolitan area (Mason and Moore, 1971). Ambrose found that rise in automobile ownership levels, indicative of increased mobility, did not affect shopping patterns (Ambrose, 1968). However, Day discovered a significant relationship between car ownership and the utilization of more than one shopping center, but the effect of other socio-economic variables on the behavior of consumers proved to be insignificant (Day, 1973).

Studies examining the influence of various socio-economic variables on the behavior of consumers in space indicate that the income variable has the greatest effect. The upper incone groups are able to incur the additional costs of traveling farther to purchase a goot, thereby enhancing their mobility. The variable of age merely produces variations between the shopping patterns of the aged and the other age groups. The variable of social status affects shopping frequency and the type of stores shopped. Upper and middle class groups shop more often and at department stores, while the lower groups shop less frequently and usually at discount stores (Rich and Jain, 1968). But this could very well be due to the factor of income more than the other components used to define social status. While variations exist between the shopping patterns of black and white shoppers, it is unclear whether these variations are attributable to residential location and income or to the factor of race. 
The failure of some of these studies to establish a strong relationship between various socio-economic variables and the behavior of consumers in space has led to the contention that variations in shopping patterns can be attributed to psychological or attitudinal differences between various consumers (Mason and Moore, 1970-71, p.37). Research has focused on the consumer's subjective interpretation of such elements as the locational convenience and accessibility of retail units; the price, quality and selection of goods; quality of service; and the atmosphere of the store or center. These elements were combined to determine the relative attractiveness of the store or center, depending on the shopping trip and associated unit (i.e., food shopping is associated with supermarkets while shopping goods trips are associated with regional shopping centers).

Studies have indicated that consumers will not a1ways travel to the nearest center to purchase an item (Clark, 1968. Marble, 1959. Thorpe and Nader, 1967. Ambrose, 1968. Clark and Rushton, 1970. Day, 1973). The phenomenon of not patronizing the nearest center has exhibited some variation depending on the type of good being purchased (Clark, 1968) and the distance to the nearest center. Likelihood of travel to a second choice center increases as distance to the nearest center increases (Clark and Rushton, 1970. Murdie, 1965).

The factor of distance, it is argued, operates in conjunction with the relative attractiveness of the store or center in the decisionmaking process (Golledge, 1967, p.247-248. Clark, 1968, p.396. Rusiton, 1969(a), p.496. Clark and Rushton, 1970. Day, 1973, p.82. Cadwallader, $1975, \mathrm{p} .344)$. The relative attractiveness of a retail center has been termed the image of the center. Following the logic of 
learring theory, the image of a store or center is established through a consuner's past experience with the retail unit. Rewarding experiences create a favorable image and adverse experiences proluce an unfavorable image resulting in consumer avoidance (Kunkel and Berry, 1968, p.22. Berry, 1969, p.5).

Numerous studies have examined the various elements comprising the image of a store or shopping center (Jonassen, 1955. Thompson, 1967. Bucklin, 1967(a). Kunkel and Berry, 1968. Berry, 1969. Thompson, 1969. Downs, 1970. Burnett, 1973. Jolson and Spath, 1973. Cadwallader, 1975). Six components have consistently defined the image of a store and center. These components have been defined in the literature as: 1) merchandise price, 2) quality of.merchandise, 3) selection of merchandise, 4) quality of service, 5). store or center atmosphere, and 6) locational convenience, with each component weighted according to the type of shopping trip (Lindquist, 1974-75). Some of these studies have shown that variations exist between socio-economic groups as to which components of the image are the nost important in the decision-making process. Thompson found that low income groups mentioned price as the most important factor in choosing a supermarket, while the middle and upper income groups indicated a preference for merchandise quality (Thompson, 1967). Singson found that the lower-lower and lower-middle socio-economic groups attached greater importance to product width (selection anong various product lines) and had a preference for general merchandise stores like Sears and Penneys, whereas the upper-lower and upper-middle groups desired product depth (selection within a specific product line) and shopped at specialized stores like Nordstrom (Singson, 1975). 
It has become well established in both geographical and marketing studies that a store or center has an image. The image is influential in the decision-making process of the consumer and helps to explain variations between socio-economic consumer groups and the irrational patterns of various consumers. While the concept of image has been accepted, it has not yet been proven conclusively that a causal connection|does exist between image and actual consumer spatial behavior.

\section{Conclusion}

The normative lọcation models of the past, particularly Christaller's central place theory, are based on the idealization of a rational economic man whose primary function is to minimize the costs of acquiring a good by visiting the nearest retail unit. The same assumption was implied in the use and development of the gravity model. The behavioral geographers have questioned the realism of these models arguing that the consumer does not necessarily optimize his trip by patronizing the nearest store or center. By rejecting the economic man assumption, however, it does not mean that the consumer is indifferent to the costs and utilities of a shopping trip. Shopping behavior can be nonoptimal while at the same time generating net travel returns that are positive (Nystuen, 1967, p.56).

Studies in consumer spatial behavior have been concerned with such concepts as action space and learning theory. Other studies have examined the influences of various socio-economic variables on consumer behavior and have found that income is the most important variable explaining differences in the spatial behavior of consumers.

Recent studies have examined the concept of the image of a store 
or center. This concept of image concerns the subjective evaluations of various elements of a store or center and their importance in the decision-making process of the consumer. It is generally accepted that certain irrational patterns of the urban consumer can be explained with respect to the image component. The relative weights of the elements comprising the image of a retail unit vary depending on the type of shopping trip and the socio-economic characteristics of the consumer. However, a causal connection between consumer behavior and the concept of image has yet to be proven conclusively. 
This study examines the components of the decision-making process utilized by the consumer in selecting a regional shopping center. In addition, shopping patterns are delimited and significant variations between the patterns of income groups and male and female shoppers are examined. These shopping patterns also are utilized to test the validity of the decision-making components derived from this study.

It should be noted that this is an idiographic study examining components in the decision-making process and the shopping patterns of consumers with regard to the regional shopping centers of Portland, Oregon. Any attempts to generalize the results of this study should be made with caution, as the physical dimensions and the social and demographic characteristics of American cities vary from place to place: The research design requires that: a) the regional shopping centers of Portland be delineated, b) a methodology be devised for the collection and analysis of data from which the major decisional components may be isolated, and c) delimitation of the shopping patterns of consumers associated with the regional shopping centers. Furthermore, hypotheses are put forth and tested through analysis of the collected data.

\section{Hypotheses}

Hypotheses are tested concerning: 1) the components integral to the decision-making process of the consumer when selecting a regional shopping center at which to shop and 2) variations in the shopping 
patterns between income groups and male and female consumers associated with Portland's regional shopping centers.

Hypothesis 1: It is generally accepted that an image, composed of the subjective evaluations of the consumer, exists of a store or center and that this image influences the decision-making process of the consumer, although a causal connection has yet to be solidly established. Typically, the most important components of the image of a store have concerned merchandise price, quality of merchandise, merchandise selection, quality of service, store atmosphere, and locational convenience. The first four components account for the greatest amount of variation (Lindquist, 1974-75).

However, with respect to a regional shopping center trip, the importance of the physical characteristics of the center in the decision-making process of the consumer is enhanced. The regional shopping center is an agglomeration of individual stores, and the physical characteristics associated with the center are those of the individual stores in conjunction with the center as a whole. This characteristic is particularly evident in the contrast between the planned and unplanned regional shopping center. The mall design, characteristic of the planned center, enhances consumer mobility between shops by eliminating the need to cross streets and protects the shopper from adverse weather conditions while supplying ample free parking. With the unplanned regional shopping center, in this case the C.B.D., the shopper must cross streets when moving from store to store while at the mercy of existing weather conditions. These conditions in association with the friction of downtown traffic and the unavailability of free parking have contributed to the demise of the C.B.D. as the 
primary shopping area throughout many of the large urban areas of the United States.

Hypothesis 2: That significant variations exist in the shopping patterns of income groups and male and female shoppers. Income groups should exhibit variations in shopping patterns with respect to the frequency of the use of regional shopping centers since upper income groups have a greater propensity to consume leading to a greater utilization of these centers. Upper income groups should also display a patronage pattern of shopping at a larger variety of Portland's regional centers due to their ability to absorb the extra costs in terms of money and time involved in shopping at a number of these centers.

With respect to male and female shoppers, the female consumer will shop more frequently than her male counterpart since the female generally has the responsibility to do the shopping, especially in family situations. If the female consumer does shop at a regional shopping center more frequently, she would have a greater knowledge of the number of such centers available and, thus, a greater propensity to use more of these centers.

\section{Delineation of Poxtland's Regional Shopping Centers.}

The delineation of Portland's regional shopping centers resulted in the specification of six such retail centers. The designation of these centers is based on their size and market areas, or just on the size of the center's market area. Following the tenets of central place theory, as applied to the urban environment by Berry (Berry, 1963), Simmons (Simmons, 1964), and Garner (Garner, 1966), the largex the 
retail center, the larger the market area of the center, such that a regional shopping center is associated with a regional market area from which it draws its customers. The physical size of the center is not the only factor affecting the corresponding market area. The type of goods, the dichotomy between convenience and shopping goods, available in the center also influences the size of the market area. That the range of a shopping good is greater than that of a convenience good is a primary proposition of central place theory. A sufficient number of shopping goods available in a center or shopping area in conjunction with some other factor of attractiveness could then establish it as a regional shopping center even though it does not have the physical size of the traditional regional shopping center in terms of retail footage. This situation now exists in many of the larger urban areas of the United States with the introduction of theme or specialty centers. These centers are frequently created by reconversion of older areas of the city which usually have some historical significance, or through the reuse of buildings such as large vacant warehouses, garages, or department stores (Redstone, 1973). These new centers are composed of artisan/specialty shops, restaurants, and in some instances, 1imited office space, but they are physically smaller than the traditional regional shopping center. Some examples of these new centers are Canal Street in Washington D.C., The Cannery and Ghiradelli Square in San Francisco, Downtown Garage South in Detroit, Ford City in Chicago, Quincy Market in Boston, Underground Atlanta in Atlanta, and Pioneer Square in Seattle. Due to their uniqueness and the agglomeration of artisan/specialty shops and restaurants, these centers are able to draw their patrons from a regional market area. Based on this ability to 
draw patrons from a large market area, these new centers could be considered as regional shopping centers, but whether or not they fit into such a category has yet to be ascertained.

of the six regional shopping centers of the Portland Metropolitan area, four were selected with regard to the number of retail establishments in the center and the retail square footage. The other two centers are examples of theme or specialty centers created through the reconversion of a historical area of Portland and the reuse of an old warehouse. (see Table I).

\section{TABLE I}

PORTLAND'S REGIONAL SHOPPING CENTERS

\begin{tabular}{lcc}
\hline & $\begin{array}{l}\text { No. of Retail } \\
\text { Establishments }\end{array}$ & Retail Footage $\left(\right.$ Ft. $\left.{ }^{2}\right)$ \\
\hline Portland C.B.D. & 456 & - \\
Lloyd Center & 112 & $1,300,000$ \\
Washington Square & 110 & $1,000,100$ \\
Jantzen Beach & 84 & 487,000 \\
John's Landing/ & 52 & 55,000 \\
Water Tower & & -- \\
Old Town & $--\infty$ & \\
\hline
\end{tabular}

Portland's CBD, Lloyd Center, Washington Square, and Jantzen Beach are examples of traditional regional shopping centers. Each is composed of two or more major department stores which serve as the main consumer atractors while the smaller specialty shops are parasitic in nature, feeding off the resulting consumer flow. Lloyd Center, Washington Square, and Jantzen Beach are examples of planned regional shopping centers characterized by a mall design with ample free parking. Jantzen 
Beach and Washington Square are relatively new centers, as they were built in 1972 and 1974, respectively. Each is a completely enclosed suburban regional shopping center located away from the CBD and represent intervening shopping opportunities. Washington Square is located in Portland's southwest suburbs in Washington County, while Jantzen Beach is located just beyond Portland's northern city limits adjacent to the southern border of the state of Washington. Lloyd Center, opened in 1960, is an anomaly in the general location patterns of planned regional shopping centers, as it was located just across the Willamette river from the CBD, thereby coming into direct competition with the CBD for the sale of shopping goods to the Portland metropolitan area (see Map 1).

John's Landing and 01d Town are examples of theme or specialty centers. 01d Town occupies an area north of but contiguous to Portland's CBD. It was in a state of physical decay until an effort was exerted to restore the area. This effort resulted in the renovation of many of the buildings with the introduction of small specialty shops and restaurants. John's Landing, or the Water Tower, which is the name of the shopping center, occupies an old warehouse in southwest Portland along the Willamette river that was renovated to accommodate small artisan/specialty shops and restaurants. John's Landing is a mixed land use development of which the shopping center is a part.

The classification of old Town and John's Landing as regionai shopping centers is based solely on their ability to attract patrons from a regional market area. It is a questionable classification due to their size and their volume of sales, both of which are considerably below those of the other four centers in this study. Another factor 


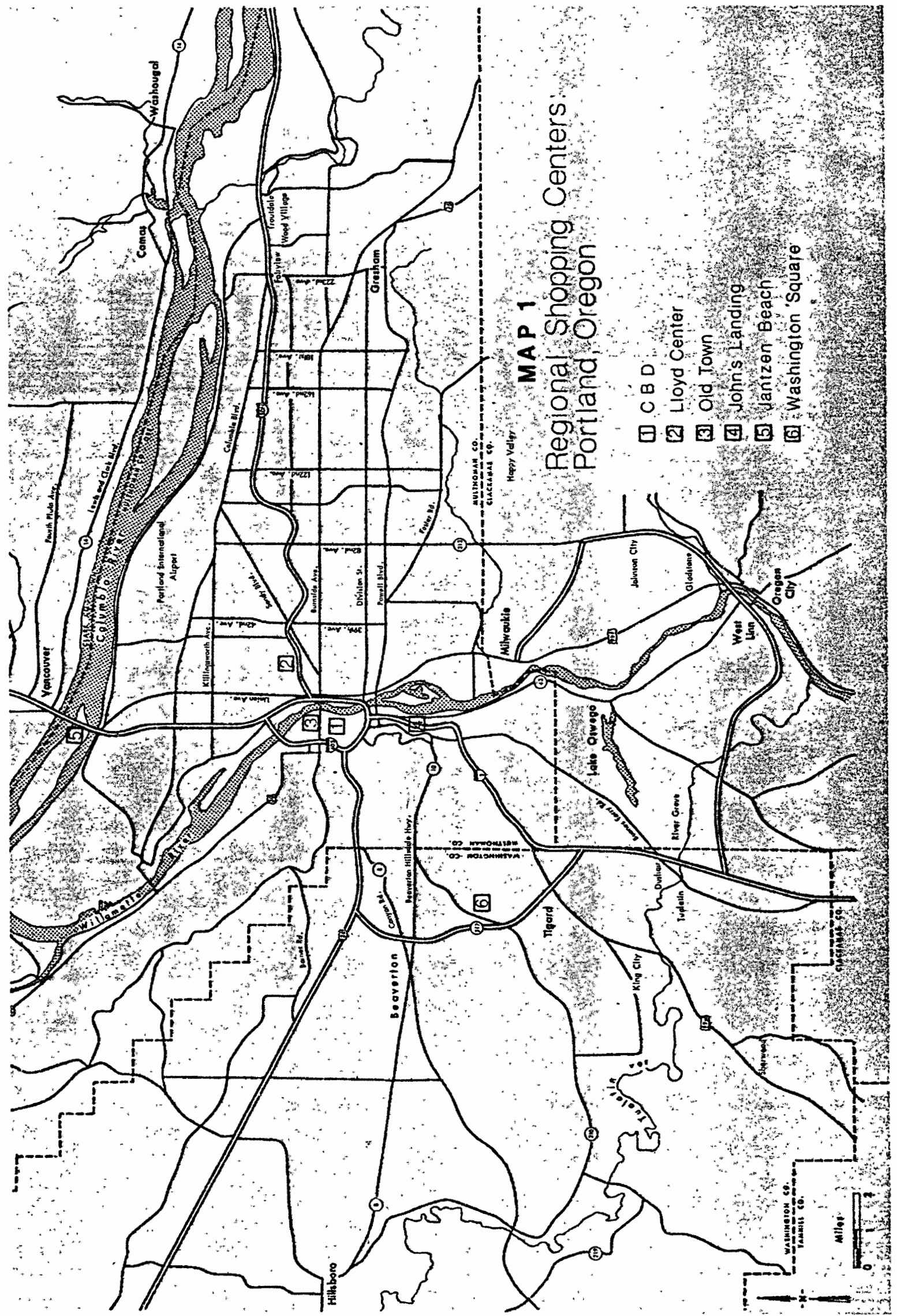


related to the market area of these theme or specialty centers concerns the characteristics of their customers. The patrons of these centers may represent a sma11, specific group of consumers, whereas the other four centers attract customers who are more representative of the general population of consumers in the Portland metropolitan area. Consequently, the number of consumers attracted to these new centers may be small when compared to the other centers although they all have large spatial markets. Since these new theme or specialty centers have not as yet come under extensive examination, particularly in geographic literature, and since they deal primarily in the sale of shopping goods to a large market area, 01d Town and John's Landing were classified as regional shopping centers for this particular study.

\section{The Suryey}

To obtain data from which the important components in the decision-making process of the consumer could be determined, a survey was conducted utilizing a questionnaire. The questionnaire requested information from which major decisional components could be derived while also requesting information indicative of consumer shopping patterns associated with the regional shopping centers of Portland. However, when conducting a survey, the researcher is faced with a number of considerations which influence the methodology employed in the survey. Two important considerations operating as constraints in this study are the time and costs involved in conducting a survey. These two constraints are reflected in the structure and administration of the questionnaire and the sample. 
Due to the constraints of time and costs, the questionnaires were self-administered to an entrapped audience according to the written instructions accompanying each questionnaire. These written instructions were reinforced with a verbal introduction prior to the administration of the questionnaire advising the respondents as to: 1) the purpose of the survey, 2) the utilization of the semantic differential, 3) that the questions should be answered in reference to the regional shopping centers of Portland, and 4) that they should proceed at a rapid pace since their initial responses were desired. Members of various classes at Portland Community College participated in the survey by completing the questionnaires, which required approximately fifteen to twenty minutes to complete. 'In this way, a number of questionnaires could be completed simultaneously. While the person to person interview is deemed the most effective technique in collecting data in a survey, it requires a great deal of time and money (Warwick and Leninger, 1975), thus making it unfeasible for this study.

A major problem with the utilization of entrapped audiences is that the results usually do not permit generalization beyond the respondents who participate in the survey (Warwick and Leninger, 1975). However, Portland Community College offers a number of diverse classes, catering not only to the academically inclined individual, but also to persons not academically oriented who are attracted to special-interest classes, such as arts and crafts, sewing, cooking, gardening, flower arranging, and photography. An effort was made to administer the questionnaires both to academically and nonacademically oriented classes. Therefore, the sample population, while suffering the bias resulting from the utilization of an entrapped audience, is more representative of 
a general population than a sample drawn from an academic setting such as a four year institution composed primarily of students with goals of achieving a degree. With the exception of an age and income bias that will be discussed later, the respondents comprising the sample did provide a good distribution of socio-economic and demographic characteristics (see Appendix 4):

The primary objective of the sample was to provide a spatially representative coverage of the Portland metropolitan area. In this respect, the shopping patterns of the respondents and the influential decisional components with regard to regional shopping centers avoided a spatial bias that would result from a clustering of respondents in space. The sample was successful in presenting a good spatial coverage of the Portland metropolitan area (see Map 2).

Portland Community College offers classes not only at its main campuses in southwest and north Portland, but also at elementary and secondary schools throughout the metropolitan area through a community education program. The sample was drawn from classes at the Sylvania campus in the southwest; the Cascade campus in the north; from Madison High School and Laurelhurst elementary school in the northeast; the Southeast Center and Franklin High School in the southeast; St. Mary's Academy and the Ross Island Extension Center in the downtown area; and Wilson and Aloha High Schools in the southwest (see Map 3).

The questionnaire is composed of three distinct parts. Thirty-six semantic differentials were employed in the first part to obtain the data necessary to isolate those components important in the decisionmaking process of the consumer. The second portion produced data indicating the shopping patterns of the respondents with regard to the 


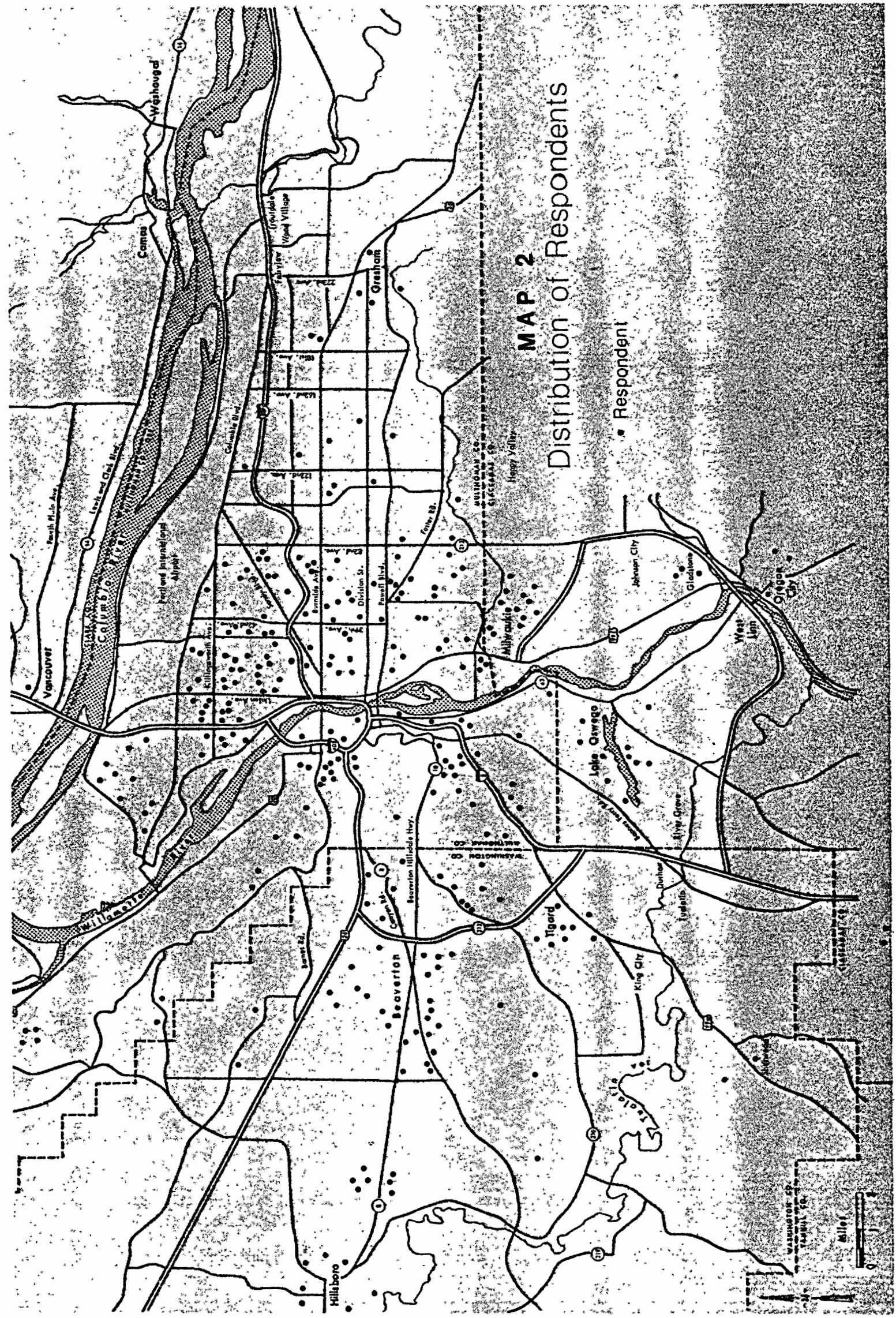




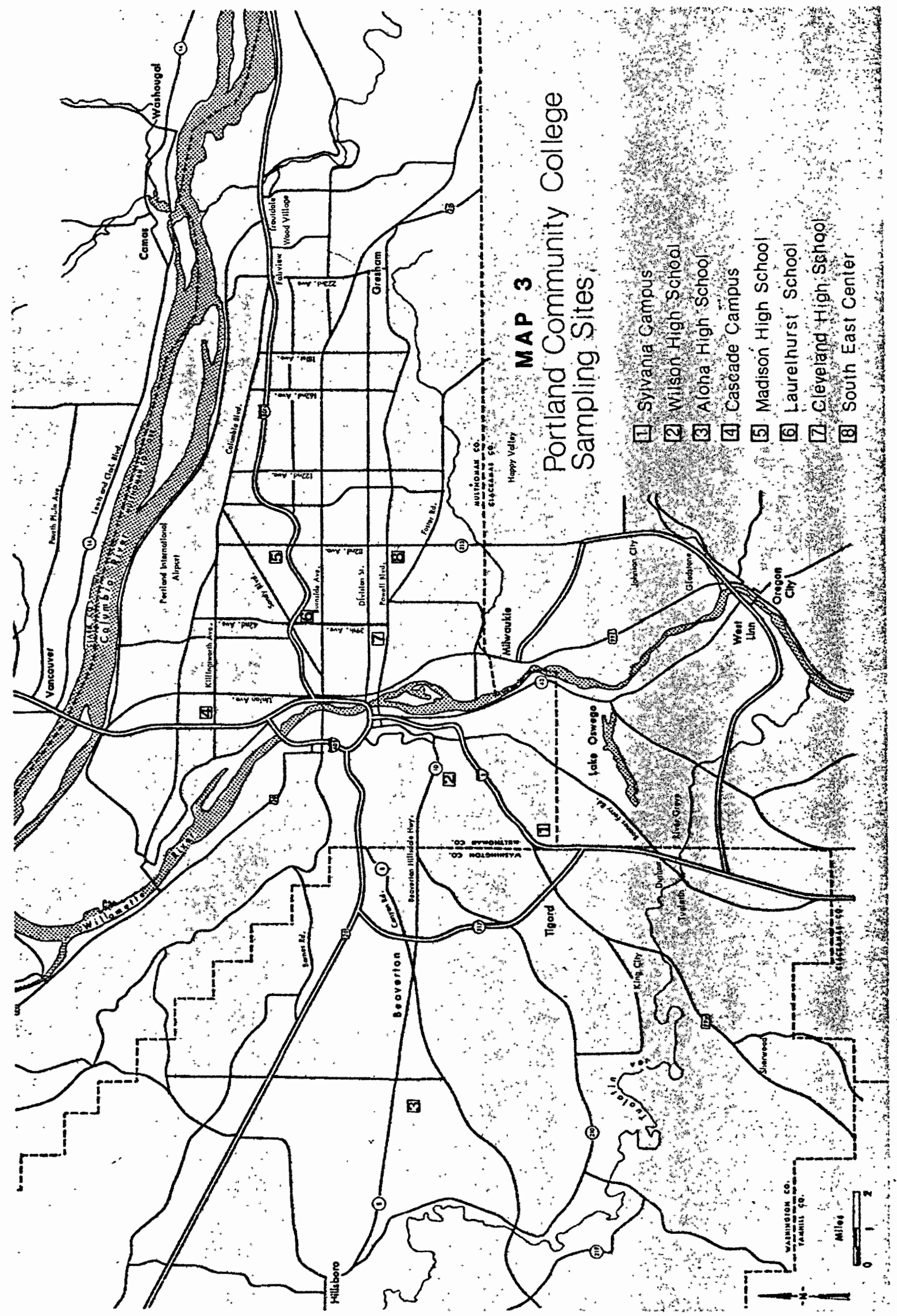


regional shopping centers of Portland. The final section obtained data pertaining to the socio-economic and demographic characteristics of the sample population.

The semantic differential, a tool frequently utilized in decisional survey research, was used to obtain data to determine the decisional components. Since the decision to shop at a particular center is. closely tied to the image the consumer has of the center, there is a process whereby the consumer subjectively evaluates the various components of the center. The semantic differential has been deemed an attractive and effective technique by which the researcher can retrieve these evaluations (Davies, 1972. Kelley and Stephenson, 1967. Mindak, 1961). The semantic differential, as developed by Osgood, Suci and Tannenbaum (Osgood, Suci and Tannenbaum, 1957), consists of bipolar adjectives or adjectival. phrases separated by a seven point scale. The respondent is presented with a concept, the stimulus, to which he reacts by marking a space along the scale. Each space along the scale indicates a direction towards one polar item or the other and an intensity of response, the distance from the neutral midpoint. The situation exists as follows:
(1)
(2)
(3)
(4)
(5)
(6)
(7)

Polar

Item $X$.
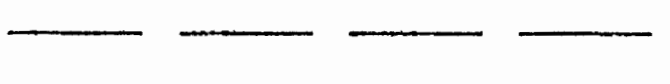

Polar Item $Y$
(1) Extremely $\mathrm{X}$
(5) Slightly Y
(2) Quite X
(6) Quite Y
(3) Slightly $x$
(7) Extremely Y
(4) Neither X or $Y$ 
In creating a semantic differential, it is important that the bipolar adjectives or adjectival phrases are meaningful or realistic to the respondents, that is, that they are valid in terms of the concept to which they are paired. The semantic differentials employed in this study were chosen on the basis of their utilization in various marketing studies of the image of stores and in the article in which Downs examIned the cognitive structure of a single regional shopping center (Downs, 1970). In this respect, the semantic differentials utilized have proven their reliability and validity. To avoid those respondents who merely check the same space throughout the questionnaire without examining each stimulus separately, the bipolar adjectives and adjectival phrases were randomly selected as to the side of the scale they would be placed. In this manner those adjectives deemed as positive, those presenting a favorable perception, were not always presented on the same side of the scale.

The semantic differential is not completely accepted as the most effective technique for the collection of data with respect to decisional research. A major criticism is that it guides the respondent as he is encouraged to respond to characteristics which do not necessarily influence his choice of a store or retail center (Berry, 1969. Kunkel and Berry, 1968. James, Derrand and Drives, 1976). Kunkel and Berry contend that the open-ended question is much more useful since it frees the respondent to discuss only those elements in the decision-making process important to him. The open-ended question, however, requires that the respondent has adequate verbal skills to respond meaningfully to the question and it requires greater interpretative skills in the analysis of the data (McDougal and Fry, 1974-75. Kelley and Stephenson, 
1967). In this respect, the semantic differential is easy to administer, it provides quantifiable data, and it requires minimal verbal skills. It has also proven to be a relatively reliable technique for the collection of data of this nature (McDougal and Fry, 1975-76. Warr and Knapper, 1968).

One other problem with the utilization of the semantic differential concerns the question of whether or not the data is ordinal or interval, leading to the problem of whether the researcher should use parametric or nonparametric statistics. Most researchers who have utilized or studied the semantic differential have concluded that the data obtained through the instrument is interval, thereby warranting the use of parametric statistics (Warr and Knapper, 1968. McDougal and Fry, 1974-75. Messick, 1969. Osgood, Suci, and Tannenbaum, 1957). The data collected in this study by the semantic differential is treated as that occupying the interval level and parametric statistics are used.

Data Analysis: Methodology

A factor analytic framework was applied to the data collected with the semantic differential to isolate the major decisional components. The function of a factor analysis model is the disentanglement of the complex interrelationships of the data into their major and distinct patterns, the factors (Catte1l, 1952. Rummel, 1967. King, 1969. Rumme1, 1970. Yeates, 1974). These factors are characterized by those variables which have high factor loadings, the correlation of the variable with each extracted factor.

A principal components analysis was employed in which it was assumed that the variables utilized in the survey accounted for all of 
the variation in the population of respondents (Rumme1, 1970, p.112-113. Yeates, 1974, p.208). Consequently, the communalities of the variables, the amount of variation that a variable has in common with respect to all of the variables, is one. An 2 mode analysis was also employed to delineate the patterns of variation within the variables.

The factors generated by a principal components analysis are ordered according to the amount of rariation that each factor defines. The first factor accounts for the zreatest amount of variation in the data. The second factor represents the next highest amount of variation, and so on to the last factors wich account for a small portion of the variation. The last variables wich account for very little variation are generally very difficult, if not impossible, to define and are ignored in the subsequent analysis leaving only those factors accounting for the greatest variation (Rummel; $: 970 ; p .112$ ).

To discern variations in the shopping patterns. of income groups, and male and female consumers, cross tabulations were utilized. Sex and income were cross tabulated with frequency of shopping at a regionall shopping center and the number of cezters utilized.

\section{Conclusion}

As with any study, the methoiology employed directly influences the interpretability and usefulness of the final results. A major consideration to be kept in mind wis examining the final results of this study concerns the sample. The sample was not random, in the sense that $a 11$ consumers had an equal prosability of being selected, so there is a certain amount of bias containes within it. As stated, classes at Portland Community College were ailized in the study. While this 
institution facilitated the prime requirement of obtaining a good spatial distribution of respondents throughout the Portland metropolitan area, the use of its classes introduced a certain amount of bias which limits the applicability of the results to a general population of consumers. The amount of bias inherent in the use of entrapped audiences, particularly college classes, was limited to some extent through the utilization of accredited and nonaccredited, special interest classes which provided a good distribution of socio-economic and demographic characteristics among the sample population. 


\section{CHAPTER IV}

\section{ANALYSIS}

The principal components analysis extracted three distinct factors defining the major decision-making components among the respondents. With. the application of an eigenvalue cutoff criterion of one or greater, ten factors were produced in the initial run. However, only three of these factors contained four or more variables with significant factor loadings of .40 or greater. The seven factors with three or less variables with significant loadings made their interpretation unfeasible.

Rummel refers to the interpretability of a factor as its meaningfulness which he defines as the subjective probability criterion for deciding the acceptability of a factor based on the configuration of the loadings and the proportion of variance accounted for by the factor (Rummel, 1970, p.356-357). The scree test was also utilized to delimit the number of factors. The scree test, as proposed by Cattell (Cattel1, 1952), is based on the proposition that as factor variance levels off the factors begin to measure random error. With the application of this test to the ten initial factors, a leveling off of variance was accounted for after the third factor. The scree test, in conjunction with the interpretability of the factors, was the basis for limiting the number of factors to three in the subsequent analysis.

An analytic rotation was applied to the three factors making them easier to interpret by simplifying their structure. An orthogonal, varimax rotation was applied making the factors orthogonal to one another, while the varimax criterion simplied the columns of the matrix. 


\section{TABLE II}

NORMAL ROTATED. FACTOR MATRIX

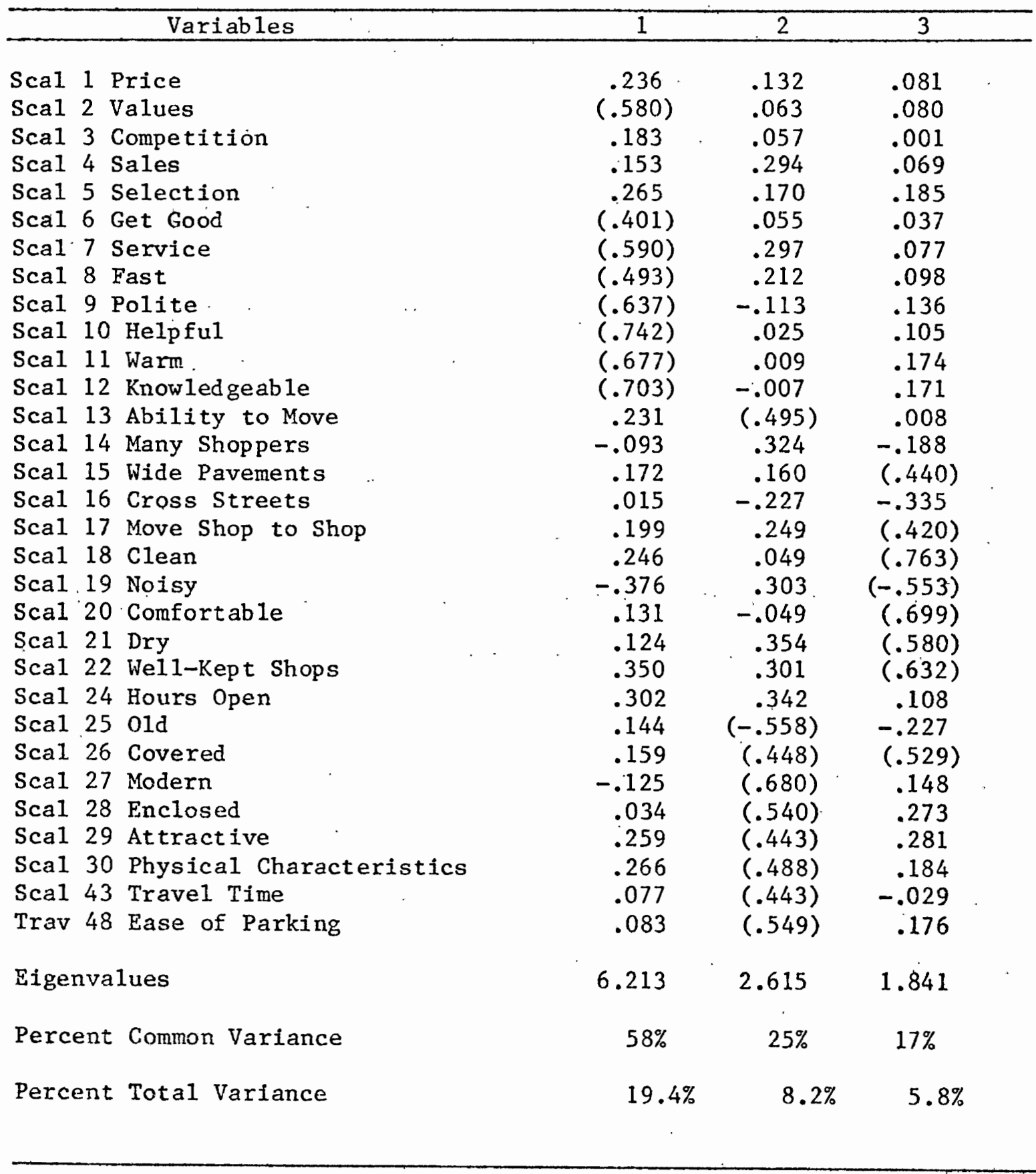


The interpretation of the three factors reflects the nature of the variables involved in each factor based on their..factor loadings. The first factor, accounting for fifty-eight percent of the common variance, has eight variables with significant loadings. Employees who are helpful, polite, knowledgeable, warm, and fast, in conjunction with the general concept of service and the offering of good values reflect a quality of service dimension (see Table II).

The other two factors support the hypothesis that the physical qualities of a center are an integral component of the decision-making process. The second factor is characterized by seven variables depicting the importance of physical characteristics with respect to the center being new, modern, covered, enclosed, and attractive where the consumer is able to move about and park with ease. This second factor, accounting, for twenty-five percent of the common variance, is interpreted as the physical characteristics component (see Table II).

The final factor depicts the importance of comfort to the consumer when selecting a center and is interpreted as consumer comfort (see Table II). Variables loading significantly on this factor are a center which is clean, comfortable, quiet, dry, and covered, with wide pavements, well-kept shops and freedom to move from shop to shop with ease. The latter two factors support the hypothesis that the importance of the physical dimensions of the center is enhanced in the decision-making process with regard to regional shopping centers. The consumer does not attach as much importance to such elements as merchandise selection, price, and quality because he apparently does not perceive a great enough variation between the regional centers of Portland with 
regard to these elements. Consequently, the physical dimensions of the center become more influential, in conjunction with the quality of service provided by the center as an aggregation of specialty shops, department stores, and restaurants.

A factor score index is utilized to assess the validity of the three decisional components. Only those individuals shopping forty percent or more at a single center were used. Each factor has an index and can be viewed as representing the attractiveness of each center on each dimension. These indexes are subsequently validated through the examination of the shopping patterns of the respondent consumers.

TABLE III

UTILIZATION OF PORTLAND'S REGIONAL SHOPPING CENTTERS

\begin{tabular}{|c|c|c|c|c|c|c|c|c|c|c|c|c|}
\hline \multirow{2}{*}{$\begin{array}{l}\text { Percent } \\
\text { Utilized }\end{array}$} & \multicolumn{2}{|c|}{$\begin{array}{c}\text { Washington } \\
\text { Square }\end{array}$} & \multicolumn{2}{|c|}{$\begin{array}{l}\text { Lloyd } \\
\text { Center }\end{array}$} & \multicolumn{2}{|c|}{$\begin{array}{c}\text { Portland } \\
\text { C.B.D. }\end{array}$} & \multicolumn{2}{|c|}{$\begin{array}{c}\text { Jantzen } \\
\text { Beach }\end{array}$} & \multirow{2}{*}{$\frac{01 d}{\text { No. }}$} & Town & \multicolumn{2}{|c|}{$\begin{array}{r}\text { John's } \\
\text { Landing }\end{array}$} \\
\hline & No. & $\%$ & No. & $\%$ & No. & $\%$ & No. & $\%$ & & $\%$ & No. & $\%$ \\
\hline $0 \%$ & 102 & $34 \%$ & 68 & $23 \%$ & 103 & $34 \%$ & 216 & $72 \%$ & 223 & $74 \%$ & 218 & $73 \%$ \\
\hline $1-10 \%$ & 49 & $16 \%$ & 56 & $19 \%$ & . 29 & $10 \%$ & 46 & $15 \%$ & 45 & $15 \%$ & 60 & $20 \%$ \\
\hline $11-20 \%$ & 20 & $7 \%$ & 29 & $10 \%$ & 32 & $11 \%$ & 12 & $4 \%$ & 14 & $5 \%$ & 10 & $3 \%$ \\
\hline $21-30 \%$ & 12 & $4 \%$ & 28 & $9 \%$ & 17 & $6 \%$ & 11 & $4 \%$ & 6 & $2 \%$ & 4 & $1 \%$ \\
\hline $31-40 \%$ & 8 & $3 \%$ & 19 & $6 \%$ & 11 & $4 \%$ & 5 & $2 \%$ & 6 & $2 \%$ & 3 & $1 \%$ \\
\hline $41-50 \%$ & 14 & $5 \%$ & 30 & $10 \%$ & 20 & $7 \%$ & 5 & $2 \%$ & 1 & $0 \%$ & 4 & $1 \%$ \\
\hline $51-60 \%$ & 11 & $4 \%$ & 9 & $3 \%$ & 6 & $2 \%$ & - & - & - & - & - & \\
\hline$-61-70 \%$ & 2 & $1 \%$ & 10 & $3 \%$ & 4 & $1 \%$ & 1 & $0 \%$ & 1 & $0 \%$ & 1 & $0 \%$ \\
\hline $71-80 \%$ & 29 & $10 \%$ & 22 & $7 \%$ & 9 & $3 \%$ & 3 & $1 \%$ & 3 & $1 \%$ & - & \\
\hline$-81-90 \%$ & 22 & $7 \%$ & 14 & $5 \%$ & 3 & $1 \%$ & 1 & $0 \%$ & - & - & - & \\
\hline$-91-100 \%$ & 31 & $10 \%$ & 15 & $5 \%$ & 1 & $0 \%$ & - & - & - & - & - & - \\
\hline
\end{tabular}

Washington Square, Lloyd Center, and Portland's C.B.D. had more 
than thirty respondents shopping forty percent or more of their time at these centers. Jantzen Beach, 01d Town, and John's Landing had equivalent respondents of ten, five and five, respectively (see Table III). Because of these low numbers, the reliability of their indexes are highly suspect and are consequently omitted from this portion of the analysis. This reflects the status of Washington Square, Lloyd Center, and Portland's C.B.D. as Portland's primary regional shopping centers, while the other three are accorded secondary status by the consumers. The index table reflects the importance of each of these factors on the decision to shop at the specific center listed in the table. Therefore, care should be exercised when interpreting the table with respect to each of the factors since these mean values are based on those respondents who shop at that particular center a majority of the time, and the elements affecting that decision vary from center to center. While the physical character component, and those variables defining that component such as new and modern, are positive with regard to a planned center, they are negative with respect to the C.B.D. This does not mean that the planned mall is more attractive, but that the respondents who shop at these centers are attracted by different variables defining the physical component than those who shop in the C.B.D. Consequently, the planned centers have higher mean values on the physical character component that does the C.B.D. due to the variables defining that component.

The index of the first factor, the quality of service, shows that Washington Square and Lloyd Center have means close to zero, indicating that they are similar with regard to this component. The C.B.D. has a negative mean value much lower than those of the other two centers, 
revealing that the downtown shopping area is not as attractive with regard to quality of service (see Table IV).

\section{TABLE IV}

FACTOR SCORE INDEX

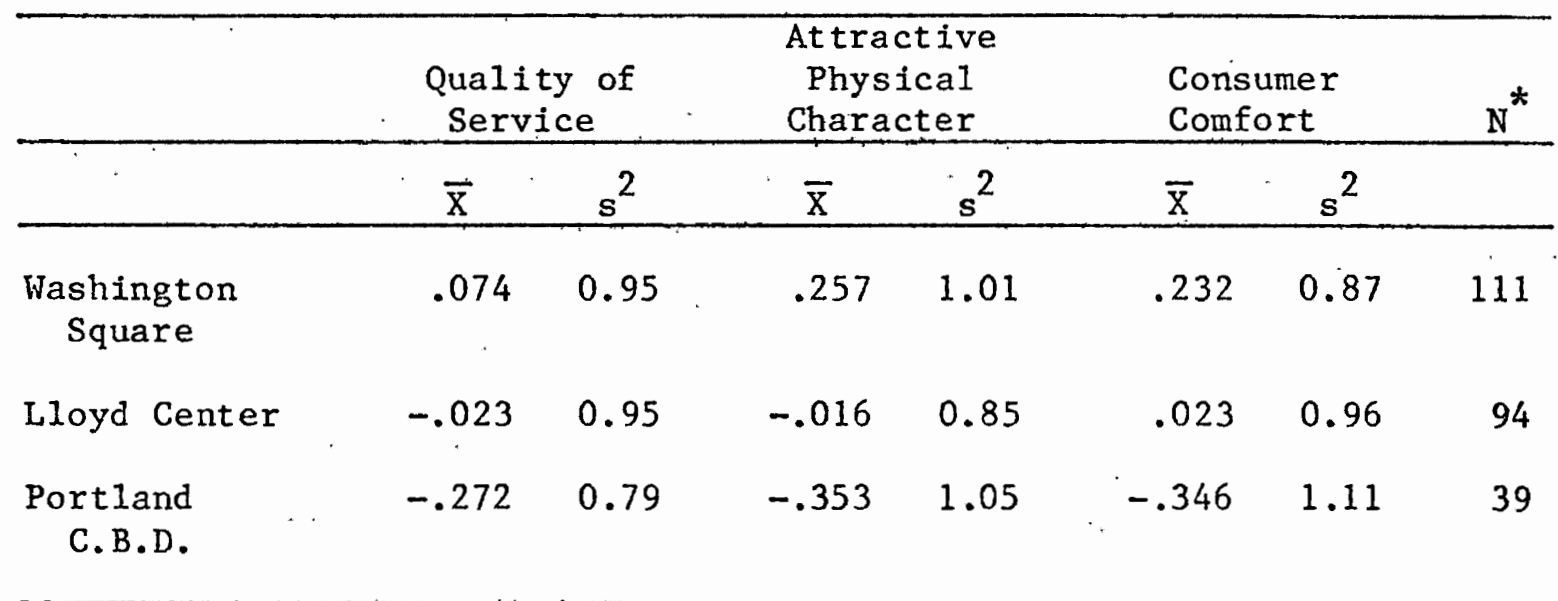

* Respondents who shop forty percent or more, as the major percentage, at one center.

The second index, the physical character, shows that Washington Square and LLoyd Center again have higher mean values than the C.B.D. Washington 'Square has the highest index because it is the newest of the three centers, the most modern, and it is completely enclosed as opposed to Lloyd Center. which is covered but not enclosed. The two planned centers are considered more attractive than the C.B.D.

The consumer comfort index enhibits the same pattern found in the prior two indexes. Washington Square and LIoyd Center are represented by mean values greater that zero without a major difference between them. The downtown area has a negative value greatly different from the other two centers. The C.B.D. on the final factor is again not as attractive as the two planned regional shopping centers. 
These three indexes icdicate that the two planned centers are more attractive than the C.B.D. A consistent pattern shows that Washington Square and Lloyd Center are more attractive (similar to one another), whereas the downtown area is less atrractive and significantly different from the other two centers. The differences between Lloyd Center and Washington Square, and Portland's C.P.D., however, are attributable to a certain extent to the reasons expressed by the respondents for shopping at these centers and will be examined later in this chapter.

An examination of selected shopping patterns of the respondent consumers is utilized to validate these indexes. These patterns indicate the relative drawing power and utilization of the three shopping centers.

\section{TABLE $\nabla$}

RELATIVE DRANING POWER

\begin{tabular}{|c|c|c|c|c|c|c|c|c|c|c|c|c|c|c|c|c|}
\hline $\begin{array}{c}\text { Shopping } \\
\text { Center }\end{array}$ & & 4 & & in. & & 14 & & $\begin{array}{l}-24 \\
\text { in. }\end{array}$ & & $\begin{array}{l}-34 \\
\text { in. }\end{array}$ & & & & & $\mathrm{N}$ & $\begin{array}{l}\% \text { of } \\
\text { Total }\end{array}$ \\
\hline & 非 & $\%$ & \# & $\%$ & it & $\%$ & 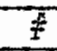 & 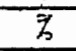 & 䠌 & $\%$ & $\#$ & $\%$ & \#F & $\%$ & & \\
\hline $\begin{array}{c}\text { Washington } \\
\text { Square }\end{array}$ & 7 & $6 \%$ & 26 & $23 \%$ & 35 & $32 \%$ & 27 & $24 \%$ & 10 & $9 \%$ & 4 & $4 \%$ & 2 & $2 \%$ & 111 & $43 \%$ \\
\hline $\begin{array}{l}\text { Lloyd } \\
\text { Center }\end{array}$ & 3 & $3 \%$ & 33 & $35 \%$ & 29 & $31 \%$ & 22 & $23 \%$ & 6 & $6 \%$ & 0 & - & 1 & $1 \%$ & 94 & $36 \%$ \\
\hline $\begin{array}{c}\text { Portland } \\
\text { C.B.D. }\end{array}$ & 5 & $13 \%$ & 4 & $10 \%$ & 11 & $28 \%$ & 15 & $39 \%$ & 4 & $10 \%$ & 0 & - & 0 & - & 39 & $15 \%$ \\
\hline $\begin{array}{r}\text { Jantzen } \\
\text { Beach }\end{array}$ & 0 & - & 2 & $25 \%$ & 2 & $25 \%$ & 1 & $12 \%$ & 2 & $25 \%$ & 0 & - & 1 & $12 \%$ & 8 & $3 \%$ \\
\hline old Town & 0 & - & 4 & $66 \%$ & 0 & - & 2 & $33 \%$ & 0 & - & 0 & - & 0 & - & 6 & $2 \%$ \\
\hline $\begin{array}{l}\text { John's } \\
\text { Landing }\end{array}$ & 0 & - & 2 & $40 \%$ & 1 & $20 \%$ & 1 & $20 \%$ & 1 & $20 \%$ & 0 & - & 0 & - & 5 & $2 \%$ \\
\hline
\end{tabular}


The relative drawing power of each center is indicated by Table V. Overall, the three primary centers, Washington Square, Lloyd Center and Portland's C.B.D., exhibit an equal drawing power with regard to driving time. Within the 0-24 minute driving time, Washington square draws $94 \%$ of its customers, Lloyd Center 92\%, and the C.B.D. 90\%. However, the C.B.D. draws $13 \%$ within the 0-4 minute range, whereas the two planned centers draw only $6 \%$ and $2 \%$ of their patrons. The C.B.D. does not draw any customers from above thirty-five minutes driving time, while Lloyd Center draws $1 \%$ and Washington Square $6 \%$ of its customers from this range. This shows that the two planned centers are able to draw customers from a greater distance, indicating the greater attractiveness of these two centers (see Table V).

The number of respondents attracted to these three centers also indicates the relative drawing power and attractiveness of each of the centers. Washington Square attracts $43 \%$ and Lloyd Center $36 \%$ of the sample population as opposed to $15 \%$ for the C.B.D. (see Table V). When these consumers are mapped according to the center they most frequently shop, it becomes evident that Washington Square, located in Portland's western suburbs, and Lloyd Center, located in northeast Portland, are the dominant retail centers. Both enjoy relatively large trade areas with the Willamette River acting as a barrier separating the two trade areas (see Maps 4 and 5). Washington Square is dominant on the west side of the river with Lloyd Center occupying a similar position in the east, while the C.B.D. draws its customers from both sides equally (see Map 6). These maps support the relative attractiveness of the centers based on the factor score index. 


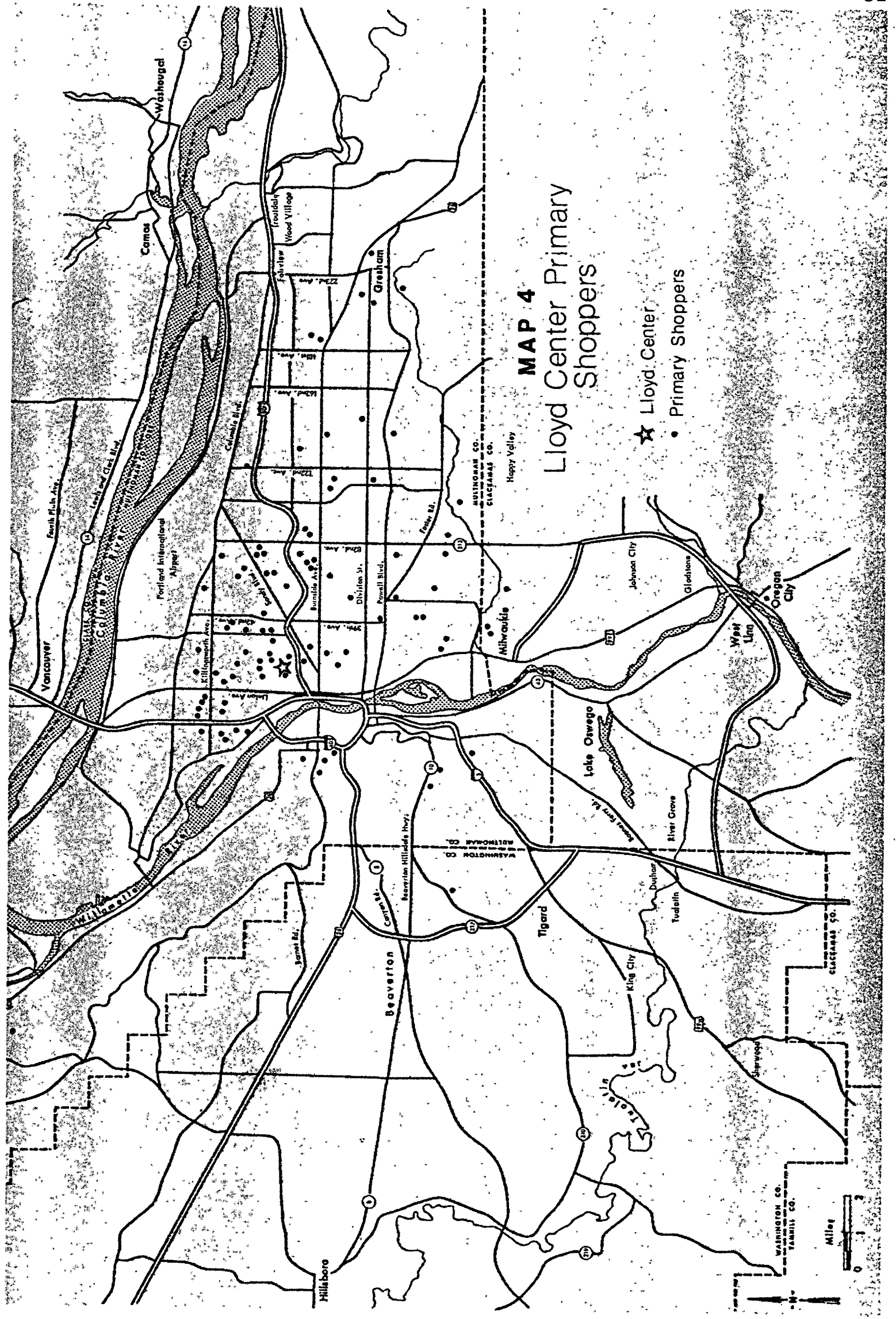




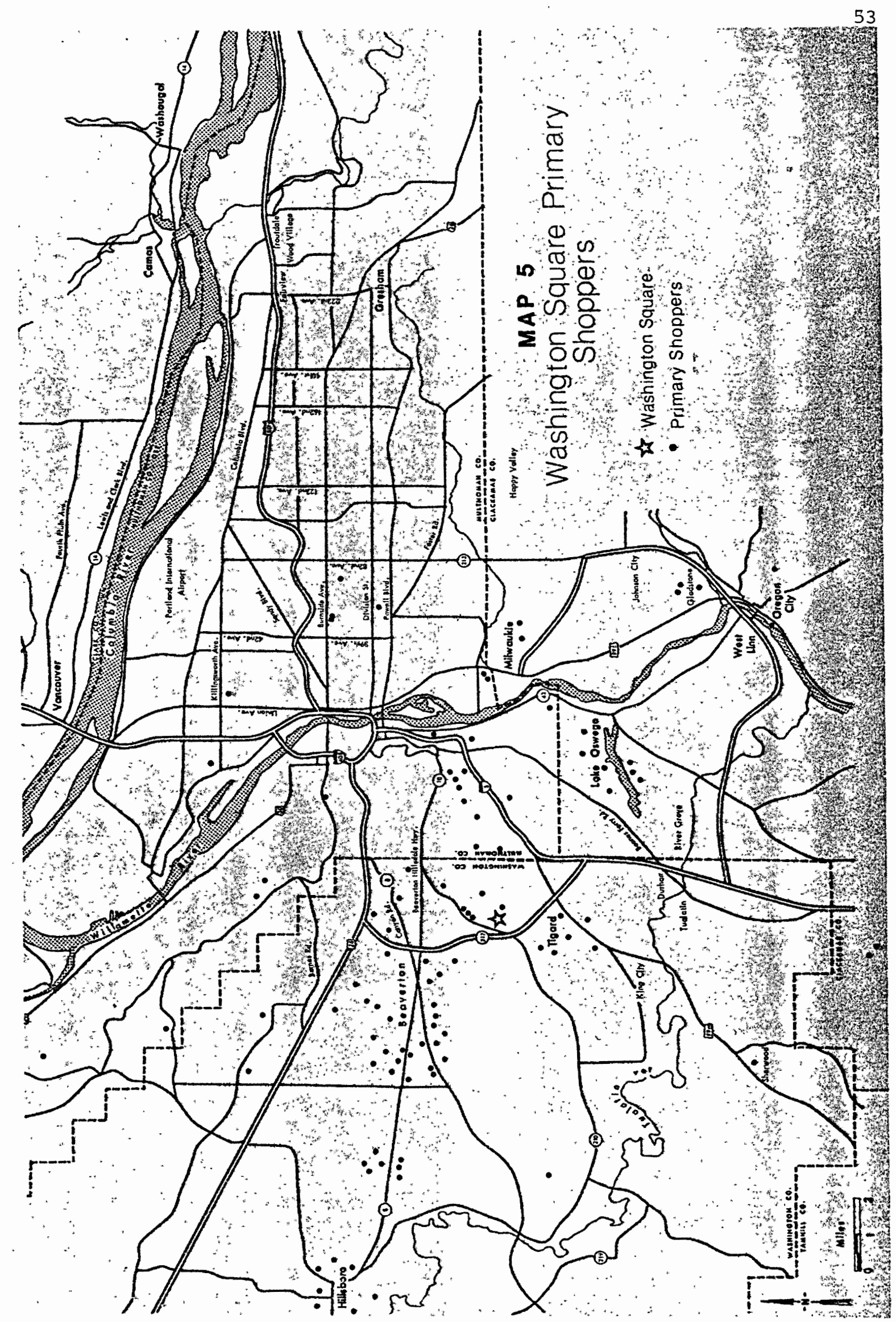




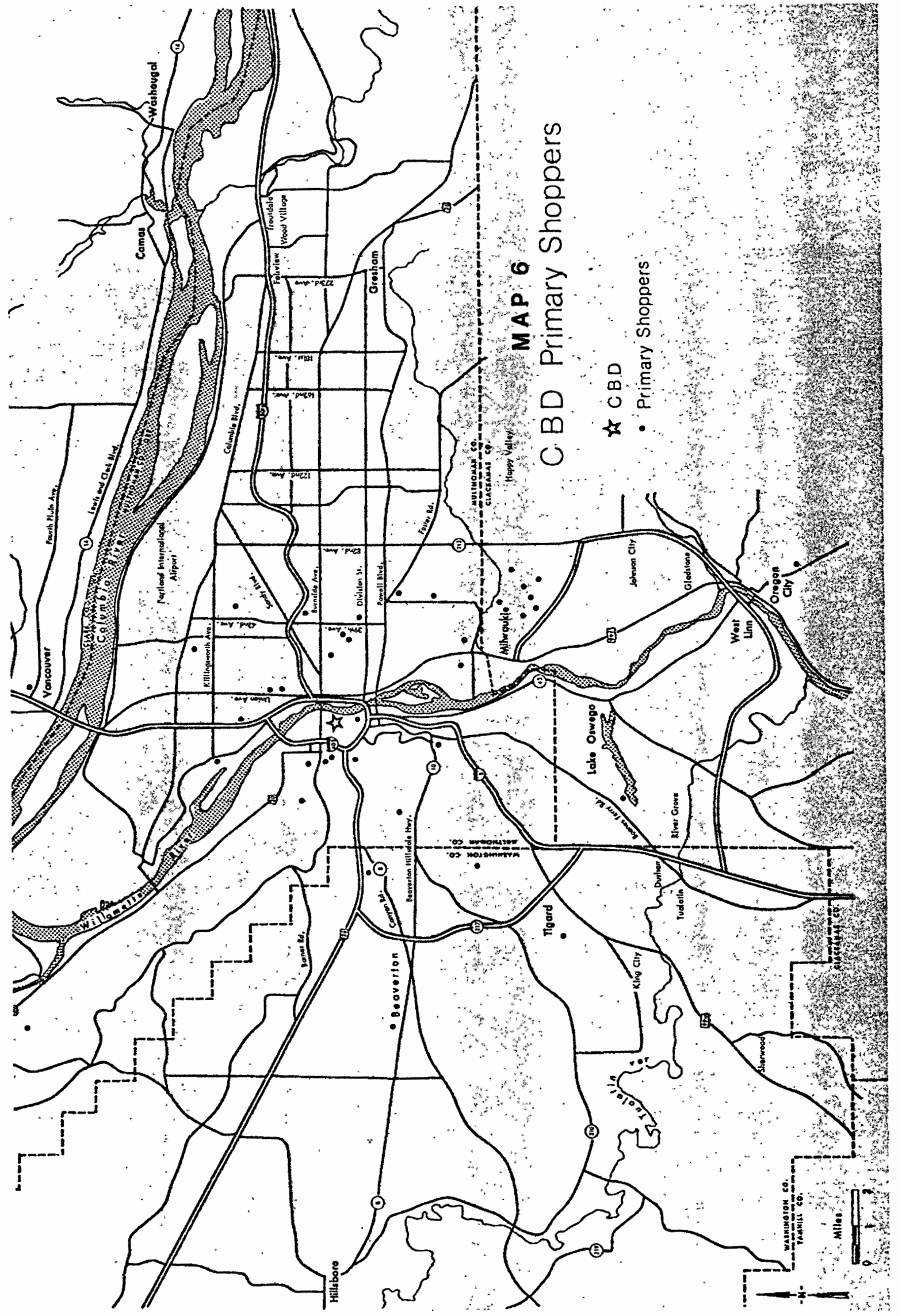


However, both distance and center size play important roles in the choice of a shopping center. Center size accounts for the relatively weak drawing power of old Town and John's Landing, neither are primary shopping centers among the sample population as each attracts only two percent of those respondents who shop fifty percent or more of the time at one center. This reflects the relatively small size of these centers, the absence of major department store anchors and their ability to attract a smal1, and quite possibly, a select group of consumers as a primary shopping center.

Jantzen Beach serves as a primary shopping center to only three percent of the respondent consumers. Part of this can be attributed to the size of the center, less than half the size of the other planned centers, and to distance. The center is not located within a densely population area or in an area of high social status.

The primary locational factor for Jantzen Beach seems to be the existence of the political boundary, the Columbia River, between the states of Oregon and Washington. Washington has a sales tax of $5.1 \%$, whereas Oregon does not have a sales tax. Consumers are presumably attracted to Oregon by the savings accrued by the absence of a sales tax. In this respect, Jantzen Beach is an intervening opportunity, as it is located adjacent to Washington and next to a major transportation corridor, I-5. If the sample had been comprised of a substantial number of consumers from Clark County, Washington, Jantzen Beach would probably have attracted a larger share of the sample, but the purpose of the study is the examination of the patterns of consumers in Portland, Oregon and this reveals that Jantzen Beach is not a primary shopping center among these consumers. 
TABIE VI

SECOND CHOTCE CENTER ANOYG LLOYD CENTER SHOPPERS

\begin{tabular}{lcc}
\hline Shopping Center & No. & $\%$ \\
\hline Portland's C.B.D. & 33 & $35 \%$ \\
Washington Square & 15 & $16 \%$ \\
Jantzen Beach & 15 & $16 \%$ \\
John's Landing & 3 & $3 \%$ \\
O1d Town & 3 & $3 \%$ \\
100\% L.C. Shopper & 7 & $8 \%$ \\
No Single Center & 13 & $19 \%$ \\
\hline
\end{tabular}

The factor of distance is important when the center shopped the next most frequently is examined. Those respondents who shop primarily at Lloyd Center, shop the second most of ten in the C.B.D. rather than travel to Washington Square (see Table VI). The distance to Washington Square is substantially greater than that to the C.B.D. for a majority of the Lloyd Center shoppers. Lloyd Center is located in northeast Portland, just east of the Hillamette River. The C.B.D., located in southwest Portland, just west of the river, is much closer to a majority of Lloyd Center's customers. The attractiveness of Washington Square is unable to override the locational convenience of the C.B.D. as a second choice center (see Map 7).

Jantzen Beach, located in Nortin Portland, is also an important second choice center being selected by the same number choosing Washington Square. This reinforces the importance of distance as Jantzen Beach was shopped the second most frequently by those consumers 


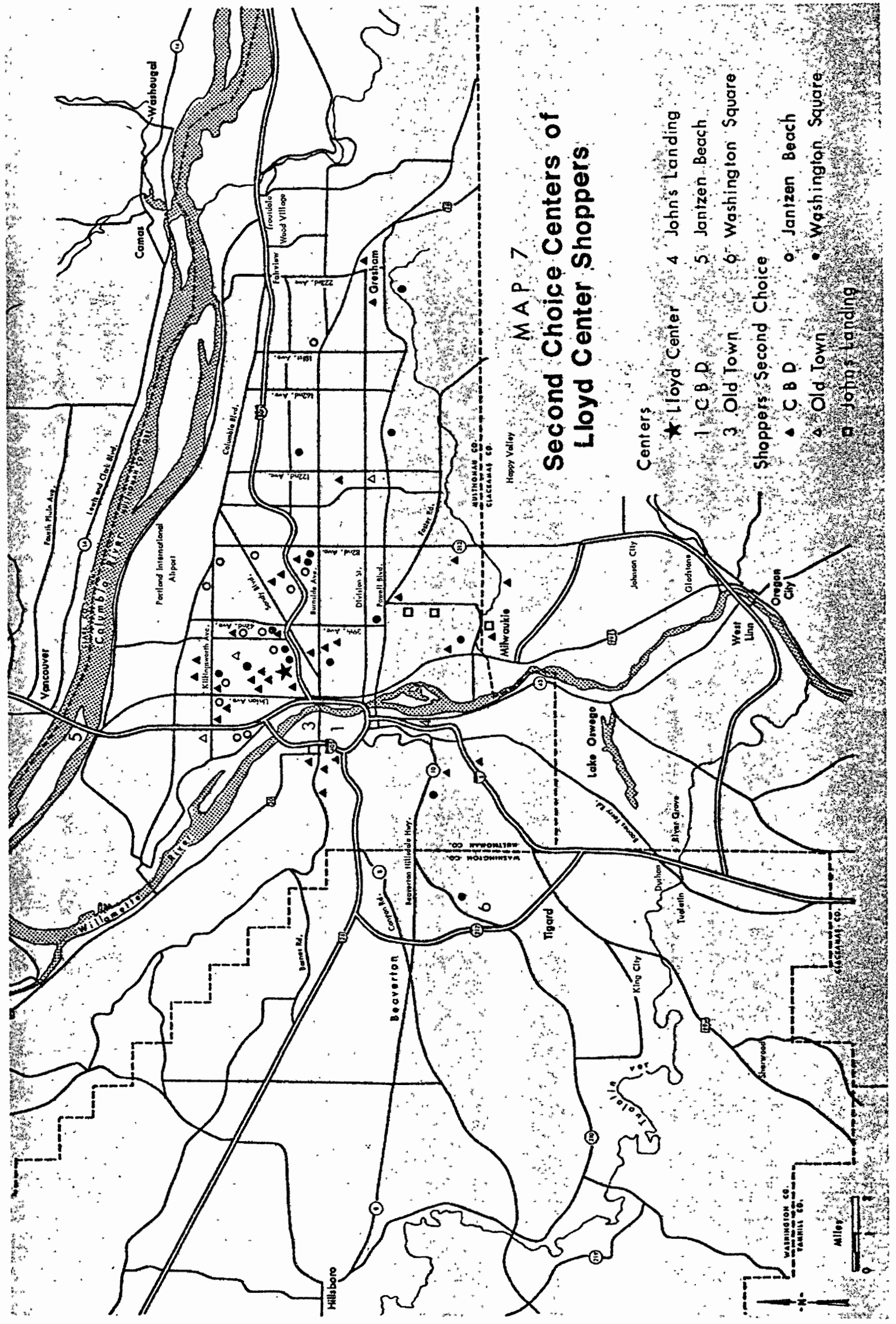


residing in North Portland (see Map 7).

The same relationship is incicated by those consumers who primarily shop in the C.B.D. (see Table VII). Lloyd Center is the second choice center among a large majority of the shoppers followed by Washington Square and Old Town. This again reflects the effects of distance, size, and the relative attractiveness of a center (see Map 8). old Town is utilized as the second choice center by $18 \%$ of the C.B.D. shoppers because of its location contiguous to the C.B.D. and its unique attractiveness as a specialty shopping area (e.g., the availability of artisan/specialty shops). Trirty-one percent indicate that they do not have a single center that they shop as a second choice center. Instead, they shop evenly at a number of centers, with combinations of old Town, Lloyd Center and Washington Square being most frequently mentioned.

TABLE VII

SECOND CHOICE CENTER AYONG C.B.D. SHOPPERS

Shopping Center No.

Lloyd Center

Washington Square

0ld Town

Jantzen Beach

John's Landing

100\% C.B.D. Shopper

No Single Center
12

5

5

3

1

1

12
$31 \%$

$13 \%$

$13 \%$

$8 \%$

$3 \%$

$3 \%$

$31 \%$ 


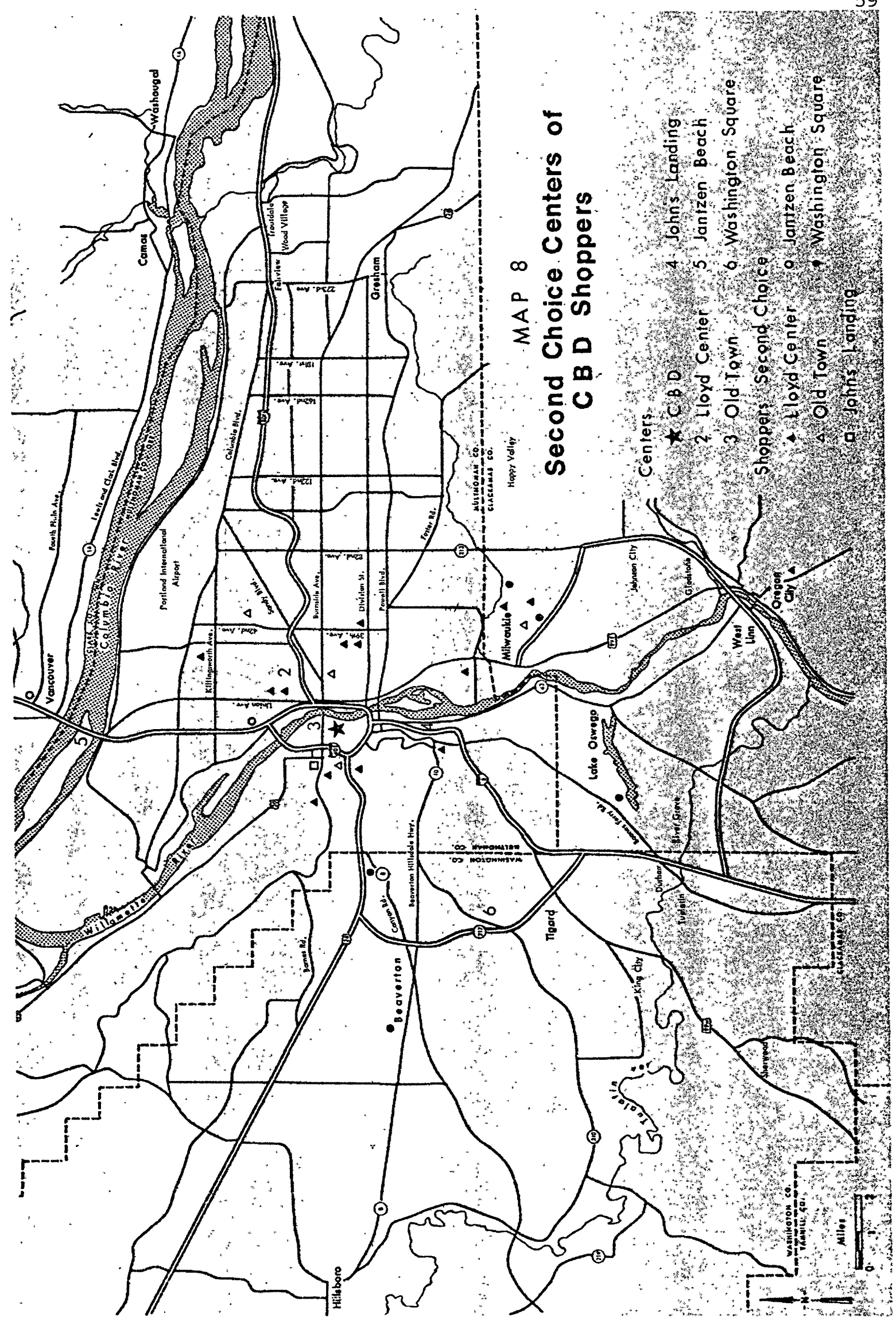


A majority of consumers tho shop primarily at Washington Square indicated Lloyd Center as the second choice center, although the C.B.D. is closer (see Table VIII). The difference in distance between the C.B.D. and Lloyd Center is small, such that the attractiveness of the latter center overrides the effect of the difference in distance (see Map 9). The costs incurred by the extra distance are essentially outweighed by the attractiveness of Lloyd Center over the C.B.D. A relatively high percent of Washington Square shoppers, fourteen percent, shop exclusively at this center. The factor of distance to the other centers seems to constrict the utility of shopping these centers for a number of consumers.

TABLE VIII

SECOND CHOICE CENTER AMONG WASHINGTON SQUARE SHOPPERS

\begin{tabular}{lcc}
\hline Shopping Center & No. & $\%$ \\
\hline Lioyd Center & 46 & $41 \%$ \\
Portland's C.B.D. & 22 & $20 \%$ \\
John's Landing & 7 & $6 \%$ \\
01d Town & 5 & $4 \%$ \\
Jantzen Beach & 1 & $1 \%$ \\
100\% W.S. Shopper & 15 & $14 \%$ \\
No Single Center & 15 & $14 \%$ \\
\hline
\end{tabular}

The possibility that the utilization of Portland's C.B.D. might be influenced by factors other than distance from home and center size led to an examination of some specific shopping patterns. These patterns 


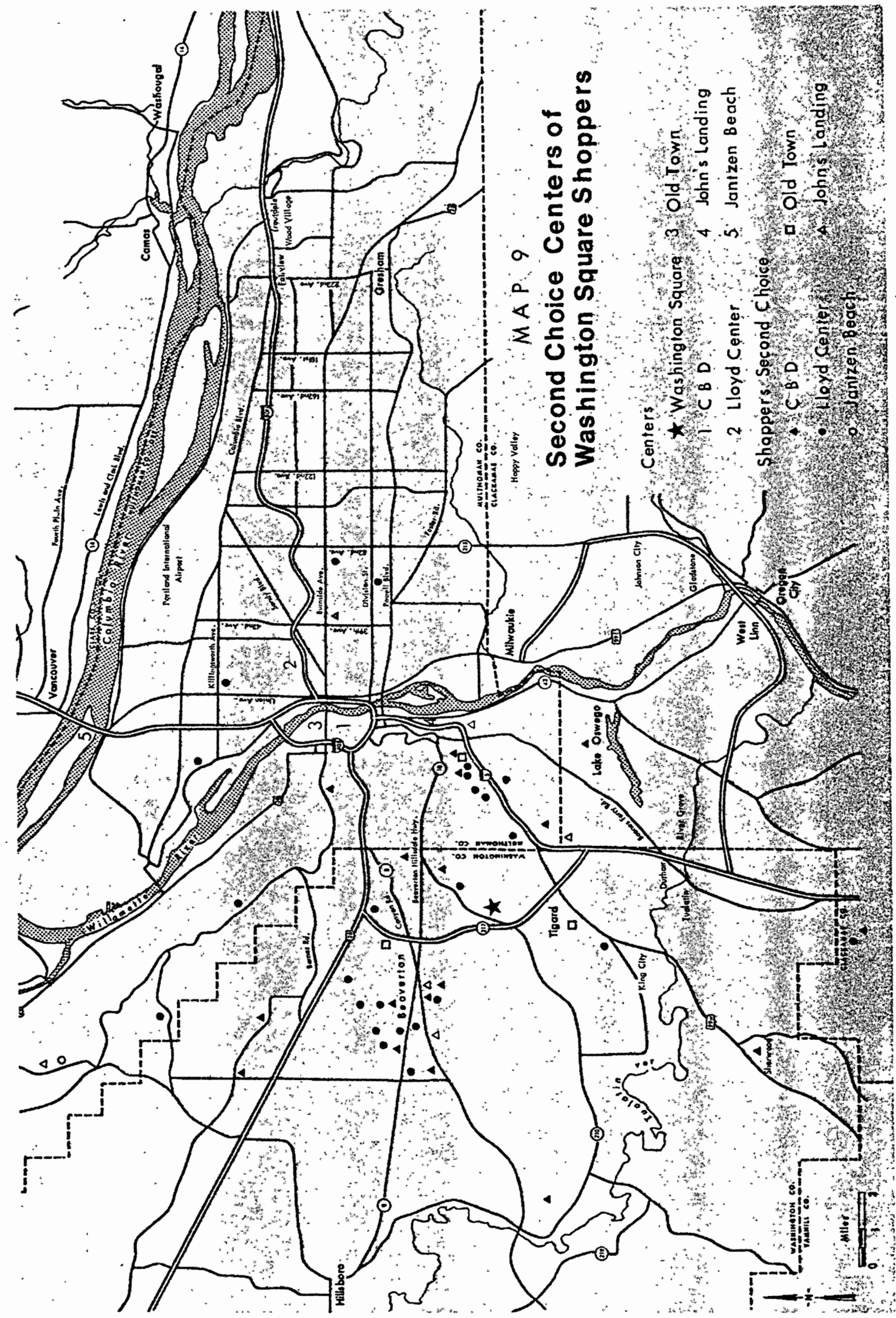


pertain to the origin point of the shopping trip and the mode of transportation.

When examining the point of origin of the shopping trip, important differences are visible between the C.B.D. and other centers (see Table IX). Ninety-five and eighty-four percent of the shoppers of Washington Square and Lloyd Center, respectively, begin their trips from home. of those respondents shopping in the C.3.D., only forty-four percent come from home. Washington Square and Lloyd Center have one and nine percent of their shoppers, respectively, coeing from work, whereas the C.B.D. has forty-four percent of its customers originating from their place of employment.

TABLE IX

POINT OF ORIGIN OZ SHOPPING TRIP*

\begin{tabular}{|c|c|c|c|c|c|c|}
\hline \multirow[b]{2}{*}{ Shopping Center } & \multicolumn{2}{|c|}{ Home } & \multicolumn{2}{|c|}{ Hork } & \multicolumn{2}{|c|}{ Other } \\
\hline & No. & $\%$ & No. & $\%$ & No. & $\%$ \\
\hline Washington Square & 106 & $95 \%$ & 1 & $1 \%$ & 4 & $4 \%$ \\
\hline Lloyd Center & 7.9. & $84 \%$ & 8 & $9 \%$ & 7 & $7 \%$ \\
\hline Portland C.B.D. & 20 & $44 \%$ & 20 & $44 \%$ & 5 & $2 \%$ \\
\hline Jantzen Beach & 7 & $88 \%$ & - & - & 1 & $2 \%$ \\
\hline $\begin{array}{l}\text { old Town \& } \\
\text { John's Landing }\end{array}$ & 11 & $92 \%$ & 1 & $8 \%$ & - & - \\
\hline TOTAL & 223 & $83 \%$ & 30 & $11 \%$ & 17 & $6 \%$ \\
\hline
\end{tabular}

* Consumers shopping forty percent or sore, as the major percentage, at ore center.

A large concentration of office workers are employed within the C.B.D. as opposed to Washington Square, having no office space avail- 
able, and Lloyd Center, which has some space. The C.B.D. functions as a shopping area for these office workers and it obviously relies on these consumers for almost half of its.sales. These office workers are shopping at a locationally convenient center either during their lunch hour or immediately after work. These consumers are shopping at the closest regional shopping center to their place of employment.

A second factor, the mode of transportation, also influences the utilization of the C.B.D. as opposed to the other centers (see Table X). Washington Square and Lloyd Center rely heavily on the consumer transported by automobile. The C.B.D. is less dependent on the automobile as only forty-three percent of its shoppers are transported by a car. Twenty-three percent of the C.B.D. shoppers rely on bus service to do their shopping. The C.B.D. maintains a comparative advantage with respect to these shoppers as it is the focal point of the mass transit system of Portland. Thirty-three percent of the C.B.D. shoppers walk, which is directly related to the number of shoppers originating from work (see Table X).

\section{TABLE $\mathrm{X}$}

MODE OF TRANSPORTATION FOR SHOPPING TRIP

\begin{tabular}{|c|c|c|c|c|c|c|c|c|c|}
\hline \multirow[b]{2}{*}{ Shopping Center } & \multicolumn{2}{|c|}{ Car } & \multicolumn{2}{|c|}{ Bus } & \multicolumn{2}{|c|}{ Wa1k } & \multicolumn{2}{|c|}{ Other } & \multirow[b]{2}{*}{ Tota1 } \\
\hline & No. & $\%$ & No. & $\%$ & No. & $\%$ & No. & $\%$ & \\
\hline Washington Square & 104 & $94 \%$ & 3 & $3 \%$ & 1 & $1 \%$ & 3 & $3 \%$ & 111 \\
\hline Lloyd Center & 81 & $86 \%$ & 3 & $3 \%$ & 5 & $5 \%$ & 1 & $1 \%$ & $94^{\prime}$ \\
\hline Portland C.B.D. & 16 & $41 \%$ & 9 & $23 \%$ & 13 & $33 \%$ & 1 & $3 \%$ & 39 \\
\hline Jantzen Beach & 8 & $100 \%$ & - & - & - & - & - & - & 8 \\
\hline $\begin{array}{l}\text { old Town \& } \\
\text { John's Landing }\end{array}$ & 11 & $100 \%$ & - & - & - & - & - & - & 11 \\
\hline
\end{tabular}


The attractiveness of the C.B.D. is apparently due to its locational convenience to a concentration of office workers. in the area and to its function as the focal point of Portland's mass transit system. However, forty-one percent of the C.B.D. shoppers are transported by automobile and are attracted to the C.B.D. by other factors.

TABLE XI

APPEAL OF TYPE OF DESIGN IN THE CONSUMER'S DECISION*

\begin{tabular}{lccccccc}
\hline Center & $\frac{\text { Traditional }}{\text { Extreme1y Quite }}$ & S1ightly & Neither & Modern \\
\hline $\begin{array}{l}\text { C.B.D. } \\
\text { Shoppers }\end{array}$ & $11 \%$ & $26 \%$ & $19 \%$ & $22 \%$ & $4 \%$ & $11 \%$ & $7 \%$ \\
$\begin{array}{l}\text { Lloyd Center } \\
\text { Shoppers }\end{array}$ & $3 \%$ & $9 \%$ & $7 \%$ & $26 \%$ & $19 \%$ & $24 \%$ & $13 \%$ \\
$\begin{array}{l}\text { Washington Sq. } \\
\text { Shoppers }\end{array}$ & $1 \%$ & $7 \%$ & $7 \%$ & $25 \%$ & $10 \%$ & $23 \%$ & $27 \%$ \\
\hline
\end{tabular}

Consumers shopping fifty percent or more of the time at either the C.B.D., Lloyd Center, or Washington Square.

Apparent1y, many C.B.D. shoppers are attracted by the physical environment of the downtown area. They find the C.B.D. appealing as a shopping area, while the new and modern planned centers do not appeal to these shoppers. This would account for the low score that the C.B.D. received on the attraction index regarding the physical characteristics of the center (see Table IV). The C.B.D. shopper is attracted by the older, more traditional design of the downtown area, whereas the Lloyd Center and Washington Square shoppers are attracted by the new, modern planned centers (see Table XI and XII). With respect to a shopping area that is open or enclosed, the C.B.D. shopper is attracted by an open 
area, while the Lloyd Center and Washington Square patron finds the enclosed center more appealing (see Table XIII).

\section{TABLE XII}

APPEAL OF THE CENTER'S AGE IN THE CONSUMER'S DECISION *

\section{Center}

C.B.D.

Shoppers

Lloyd Center

Shoppers

Washington Sq. Shoppers
$01 \mathrm{~d}$

Extremely Quite Slightly Neither Slightly Quite Extremely

$7 \%$

$22 \%$

$15 \%$

$11 \%$

$11 \%$

shoppers *Consumers shopping fifty percent or mor
C.B.D., Lloyd Center or Washington Square.

Consumers shopping fifty percent or more of the time at either. the

TABLE XIII

APPEAL OF AN OPEN OR ENCLOSED SHOPPING AREA*

\begin{tabular}{lccccccc}
\hline Center & Epen & Extremely & Quite & Slightly. Neither & S1ightly & Quite & Enclosed \\
\hline $\begin{array}{l}\text { C.B.D. } \\
\text { Shoppers }\end{array}$ & $11 \%$ & $33 \%$ & $11 \%$ & $7 \%$ & $7 \%$ & $7 \%$ & $22 \%$ \\
$\begin{array}{l}\text { Lloyd Center } \\
\text { Shoppers }\end{array}$ & $4 \%$ & $19 \%$ & $13 \%$ & $16 \%$ & $7 \%$ & $26 \%$ & $16 \%$ \\
$\begin{array}{l}\text { Washington Sq. } \\
\text { Shoppers }\end{array}$ & $5 \%$ & $1 \%$ & $3 \%$ & $7 \%$ & $6 \%$ & $20 \%$ & $56 \%$ \\
\hline
\end{tabular}

*Consumers shopping fifty percent or more of the time at either the C.B.D., Lloyd Center or Washington Square. 
To assess the validity of the second hypothesis, regarding variations in the shopping patterns of male and female consumers, and different income groups, the cross-tabulations of the frequency of shopping at a regional shopping center and the number of centers shopped by sex and income were examined. These cross-tabulations support the hypothesis that variations exist, but the differences in some cases are not great.

TABLE XIV

NUMBER OF CENTERS UTILIZED BY SEX

\begin{tabular}{|c|c|c|c|c|c|c|c|}
\hline Sex & 1 & 2 & $\frac{\sqrt{u m b e}}{3}$ & $\begin{array}{c}\text { Centers } \\
\end{array}$ & 5 & 6 & Never Shop \\
\hline Male & $12 \%$ & $29 \%$ & $29 \%$ & $16 \%$ & $3 \%$ & $6 \%$ & $5 \%$ \\
\hline Female & $6 \%$ & $27 \%$ & $33 \%$ & $19 \%$ & $8 \%$ & $6 \%$ & $1 \%$ \\
\hline
\end{tabular}

With respect to variations between male and female consumers, Table XIV indicates that female consumers utilize more of the centers than do the male shoppers (see Table XIV). Of the male shoppers, twelve percent use only one of the centers as opposed to six percent of the female shoppers. A somewhat higher percent of the women consumers shop at three or more centers than do their male counterparts, sixty-six and fifty-four percent, respectively. Women consumers also indicate a greater propensity to utilize these centers for purposes other than shopping (e.g., restaurants, theaters and special events). See Table $\mathrm{XV}$. 
TABLE XV

FREQUENCY OF SHOPPING BY SEX

\begin{tabular}{lcccccc}
\hline Sex & $\begin{array}{c}\text { More Than } \\
\text { Once A Month }\end{array}$ & $\begin{array}{c}\text { Once A } \\
\text { Month }\end{array}$ & $\begin{array}{c}\text { More Than Four } \\
\text { Times A Year }\end{array}$ & $\begin{array}{c}\text { Less Than Four } \\
\text { Times A Year }\end{array}$ & Never \\
\hline \multirow{2}{*}{ Male } & $45 \%$ & $24 \%$ & $19 \%$ & $7 \%$ & $5 \%$ \\
Female & $53 \%$ & $24 \%$ & $19 \%$ & $3 \%$ & $1 \%$ \\
& & & & & \\
\hline
\end{tabular}

Part of these differences can be explained by the frequency of shopping by sex. Fifty-three percent of the women consumers patronize a regional shopping center more than once a month as compared to forty-five percent of the male shoppers (see Table XVI). But the difference between these two figures is not great and the differences are at the extremes. Within the middle range, male and female shoppers indicate identical patterns. This pattern does not truly support the second part of the hypothesis contending that female consumers shop more frequently than male shoppers. However, when women consumers do shop, they indicate a tendency to utilize more centers than their male counterparts.

TABLE XVI

USE OF CENTERS FOR OTHER THAN SHOPPING

\begin{tabular}{lll}
\hline Sex & No & Yes \\
\hline Male & $58 \%$ & $42 \%$ \\
Female & $46 \%$ & $54 \%$ \\
\hline
\end{tabular}


that upper income groups shop more frequently than lower income groups. As income increases, the frequency of shopping a regional shopping center increases (see Table XVII). Since the regional shopping center offers high order goods, the upper income groups are better able to afford more frequent purchases of these goods.

\section{TABLE XVII}

NUMBER OF CENTERS SHOPPED BY INCOME

\begin{tabular}{lrrrrrr}
\hline & 1 & 2 & 3 & 4 & 5 & 6 \\
\hline Less than $\$ 5,000$ & $12 \%$ & $28 \%$ & $34 \%$ & $17 \%$ & $4 \%$ & $5 \%$ \\
$\$ 5,000-\$ 10,000$ & $10 \%$ & $29 \%$ & $31 \%$ & $12 \%$ & $8 \%$ & $10 \%$ \\
$\$ 10,000-\$ 15,000$ & $8 \%$ & $38 \%$ & $23 \%$ & $20 \%$ & $8 \%$ & $3 \%$ \\
$\$ 15,000-\$ 25,000$ & $9 \%$ & $28 \%$ & $28 \%$ & $22 \%$ & $5 \%$ & $9 \%$ \\
$\$ 25,000+$ & $8 \%$ & $19 \%$ & $51 \%$ & $19 \%$ & $3 \%$ & - \\
\hline
\end{tabular}

However, with regard to comparisons between income groups and the number of centers shopped, Table XVIII indicates that there are no major differences. Twelve percent of the lower income group of $\$ 15,000$ or less shop at only one center as opposed to eight percent of the highest income group of 25,000 dollars or more, a range of only four percent. No real pattern exists which would indicate that as income increases, there is an increase in the number of centers utilized, an expression of consumer mobility (see Table XVIII). The only major difference regards those shopping at three centers, where the highest income group exhibits a percentage figure significantly higher than any of the other income groups, but beyond three centers this group is below the other groups. 
TABLE XVIII

FREQUENCY OF SHOPPING BY INCOME

\begin{tabular}{lccccc}
\hline & $\begin{array}{c}\text { More Than } \\
\text { Once A Month }\end{array}$ & $\begin{array}{c}\text { Once A A } \\
\text { Month }\end{array}$ & $\begin{array}{c}\text { More Than } \\
\text { Four Times } \\
\text { A Year }\end{array}$ & $\begin{array}{c}\text { Less Than } \\
\text { Four Times } \\
\text { A Year }\end{array}$ & Never \\
\hline Less Than $\$ 5,000$ & $41 \%$ & $24 \%$ & $30 \%$ & $3 \%$ & $3 \%$ \\
$\$ 5,000-\$ 10,000$ & $53 \%$ & $26 \%$ & $17 \%$ & $2 \%$ & $2 \%$ \\
$\$ 10,000-\$ 15,000$ & $45 \%$ & $27 \%$ & $14 \%$ & $11 \%$ & $3 \%$ \\
$\$ 15,000-\$ 25,000$ & $56 \%$ & $23 \%$ & $10 \%$ & $6 \%$ & $4 \%$ \\
$\$ 25,000$ & $51 \%$ & $29 \%$ & $24 \%$ & $3 \%$ & $3 \%$ \\
\hline
\end{tabular}

Part of this pattern can be explained by the spatial distribution of Portland's regional shopping centers. The C.B.D., Lloyd Center, 01d Town, John's Landing, and to some extent, Jantzen Beach as a second choice center, are accessible to a large population of consumers east of the Willamette River (see Maps 1 and 2). Because the spatial differences separating these centers is not great, they comprise a set of retail opportunities that are accessible to a large concentration of consumers. Consequently, many consumers are able to utilize, a number of these centers due to their spatial accessibility. An examination of Table 3 shows that twenty-seven percent of Washington Square shoppers patronize the center seventy percent or more of the time as compared to seventeen percent of Lloyd Center shoppers (see Table III). This indicates that these shoppers do not patronize other centers as of ten. Map 4 shows that many of Washington Square's primary shoppers must traveI longer distances in order to shop at Portland's other regional centers. 
It also should be noted that there is a problem inherent in the sample. The low income group is comprised predominantly of the lowest age group of respondents, twenty-four or younger (see Table IXX). This indicates that many of these respondents are students who are probably living at home. While their personal income is low, their family income could well be in the upper income group, thus enhancing their mobility. This would explain the greater percentages of low income consumers shopping at a number of centers. A more representative sample of a general population, particularly of low income families, could produce a shopping pattern more supportive of the hypothesis that upper income consumers tend to utilize more centers.

TABLE IXX

DISTRIBUTION OF INCOME BY AGE GROUPS

\begin{tabular}{lccccc}
\hline & $\begin{array}{c}\text { Less Than } \\
\$ 5,000\end{array}$ & $\begin{array}{c}\$ 5,000- \\
10,000\end{array}$ & $\begin{array}{c}\$ 10,000- \\
15,000\end{array}$ & $\begin{array}{c}\$ 15,000- \\
25,000\end{array}$ & $\$ 25,000+$ \\
\hline Lo-24 yr. & $74 \%$ & $47 \%$ & $18 \%$ & $5 \%$ & $2 \%$ \\
$25-29 \mathrm{yr}$. & $21 \%$ & $21 \%$ & $32 \%$ & $19 \%$ & $14 \%$ \\
$30-39 \mathrm{yr}$. & $3 \%$ & $20 \%$ & $23 \%$ & $40 \%$ & $36 \%$ \\
$40-49 \mathrm{yr}$. & $1 \%$ & $4 \%$ & $13 \%$ & $25 \%$ & $28 \%$ \\
$50-59 \mathrm{yr}$. & $1 \%$ & $6 \%$ & $14 \%$ & $10 \%$ & $16 \%$ \\
$60+\mathrm{yr}$. & $1 \%$ & $2 \%$ & - & $1 \%$ & $3 \%$ \\
\hline
\end{tabular}

When controlling for sex and cross-tabulating income by frequency of shopping, a strong pattern surfaces among the female shoppers. As before, there is an increase in the frequency of shopping with an increase in income, but the difference between the upper income group of 
$\$ 15,000$ or more, and the other two income groups is significant, seventy percent of the higher income consumers shop more than once a month as compared to forty-seven and forty-three percent for the other two categories (see Table XX). The pattern among male income groups indicates that the middle group shops more often, fifty-one percent shop more than once a month, followed by the upper income group at forty-four percent and the lower group at thirty-eight percent. (see Table XX). With respect to the upper income group, the difference between the male and female shopper is substantial, indicating that within this group of consumers, the women shop at a regional shopping center much more of ten than their male counterparts. This shows that the difference of shopping frequency at a regional shopping center between male and female consumers is accounted for by the significant difference between the male and female consumers of the high income group. This pattern is more supportive of the second hypothesis concerning the frequency of shopping and variations between male and female shoppers.

Conclusion

Through the utilization of principal components analysis, three major decisional components were isolated with regard to the selection of regional shopping centers by the respondents. They are the quality of service, the physical character, and the consumer comfort associated with the regional shopping centers of Portland, Oregon. The first hypothesis was supported with the isolation of the physical character and consumer comfort components as important factors in the decisionmaking process of the consumer. 
TABLE XX

FREQUENCY OF SHOPPING AMONG FEMALE AND MALE INCOME GROUPS

\begin{tabular}{cllll} 
More Than & & More Than & Less Than \\
Once A & Once A & Four Times & Four Times & \\
Month & Month & A Year & A Year & Never \\
\hline
\end{tabular}

Female Consumers

$\begin{array}{llllll}\text { Less Than } \$ 5,000 & 43 \% & 26 \% & 29 \% & - & 2 \% \\ \$ 5,000-15,000 & 47 \% & 30 \% & 15 \% & 7 \% & 2 \% \\ \$ 15,000+ & 70 \% & 14 \% & 16 \% & - & -\end{array}$

Male Consumers

\begin{tabular}{llllll} 
Less than $\$ 5,000$ & $38 \%$ & $21 \%$ & $32 \%$ & $6 \%$ & $3 \%$ \\
$\$ 5,000-15,000$ & $51 \%$ & $23 \%$ & $16 \%$ & $7 \%$ & $4 \%$ \\
$\$ 15,000+$ & $44 \%$ & $27 \%$ & $15 \%$ & $8 \%$ & $6 \%$ \\
\hline
\end{tabular}

The decisional components were validated by the attractiveness index composed of factor scores, and by the examination of the shopping patterns of consumers regarding the drawing power of each of the centers, the centers primarily shopped, and the second choice centers. The attraction index indicates that of Portland's three primary centers, Washington Square and Lloyd Center are more attractive than the C.B.D. to a majority of the consumers. The shopping patterns of these consumers also supported the relative attractiveness of these centers. Many of the primary shoppers of the C.B.D. are attracted by its physical environment, while they find the planned regional shopping centers to be unattractive. In addition, the locational convenience of the C.B.D. to a large concentration of office workers and the advantage 
the C.B.D. enjoys by being the focus of the mass transit system contribute to its function as a primary shopping area.

Jantzen Beach, the other planned regional center, is a secondary center as only two percent of the respondents primarily shop at this center. The center is located away from the major concentration of Portland's consumers, but it is located in such a way as to intercept consumers from Washington who shop in Oregon. The center is shopped as a second cholce by a number of Lloyd Center primary shoppers who predominantly reside in North Portland.

The specialty centers of John's Landing and 01d Town also function as secondary centers. Because of their restricted size, they are not able to compete effectively with Portland's other regional shopping centers. Seventy-three and seventy-four percent, respectively, never shopped at these centers (see Table III). They are not regional shopping centers, but they do not fit any other shopping center classification found in geographical literature. As specialty centers, they offer an alternative selection of goods, primarily handcrafted and imported shopping goods. The restaurants found in these centers are not of the fast food variety, but they offer a pleasant dining environment and they are a main attraction of these centers. After these centers become better established, a study should be done examining theix image, market area, and the types of consumers who visit them.

The hypothesis that variations exist between male and female shoppers, and among income groups with respect to the frequency of shopping and the number of centers utilized was not wholly supported. Female consumers do shop more frequently than the male consumer, but the difference is minimal and not conclusive. Regarding differences based 
on sex and the number of centers shopped a greater variation exists as the female shopper utilizes more of the centers than does the male shopper.

A consistent pattern indicates that as income increases, there is a corresponding increase in the frequency of shopping at a regional shopping center. When sex was controlled, and income and frequency of shopping were cross-tabulated, female shoppers exhibited a significant difference in the frequency of shopping regional shopping centers between the $\$ 15,000$ or more income group and the other two groups. Interestingly, the difference in frequency between the male and female shoppers of the upper income group is substantial as seventy-percent of the female consumers shop more than once a month as opposed to fortyfour percent of the males (see Table XX). Since the upper income group shops more frequent1y than the lower groups, and the variation between male and female shoppers in this category is high, that portion of the hypothesis pertaining to variations between male and female shoppers is supported to some extent.

When the number of centers utilized was examined with regard to income, no real pattern of variation was indicated. Part of this is a function of the spatial distribution of the centers. Another explanation is the problem inherent in using a college population from which to draw a sample. Seventy-five percent of the low income group is twentyfive years of age or younger indicating a portion of students many of whom are probably living at home. Rather than representing low income families, they are more representative of middle and high income families. 


\section{DISCUSSION}

The three components derived from this study. indicate that the quality of service and the physical character and environment of a regional shopping center are important in the decision-making process of the consumer. The quality of service is the most important component, accounting for the greatest amount of variation, and concerns the quality of the sales personnel and the customer's ability to get the desired good at good values. The service dimension pertains to the center as a whole composed of the individual stores and the sales persons operating each unit. Sales personnel who are friendly, helpful, courteous, fast, and knowledgeable about the good which they are selling are important elements of this dimension. The ability of the center to provide the desired good at good values are also integral factors in the service dimension. Both Washington Square and Lloyd Center have an advantage over the C.B.D. with regard to this decisional dimension.

The second component concerns the physical characteristics of the center: its age, design, facility for internal movement, ease of parking, travel time, and whether it is open, enclosed, or covered. Consumers who are attracted by the planned regional shopping center find the new and modern features of these centers with ample amounts of free parking to be particularly appealing. The C.B.D. shopper finds the artificial environment of the planned center unappealing because they are attracted by the open and traditional environment of the downtown shopping area. 
The final component, accounting for the least amount of variation, concerns the comfort of the consumer when shopping in a regional center. A shopping environment which is clean and quiet, where the consumer is protected from weather conditions and whose movement is relatively unrestricted is an appealing feature of the planned regional shopping center. These centers, with their mall design, has an advantage over the unplanned C.B.D. where shoppers contend with automobile traffic and its associated noise and pollution of the air, and where the consumer is at the mercy of existing weather conditions when moving from store to store.

These three decisional components indicate that with regard to regional shopping centers, the elements of merchandise price, selection, and quality, frequently described as the most important factors when selecting an individual store to patronize, are not as important when choosing a regional shopping center. The development of the planned suburban regional shopping center has placed them on a level equal to the C.B.D. in terms of the price, selection, and quality of merchandise available. The important components of the decision-making process of the consumer are the quality of service, the physical character of the center, and the ability of the center to provide a comfortable shopping environment for the consumer.

This explains the advantage now enjoyed by the planned mall center, such as Washington Square and Lloyd Center, over the unplanned C.B.D., and the corresponding decline of the C.B.D. as a major shopping area. The advantages of Portland's C.B.D. lie in its locational convenience to a large concentration of office workers, its function as the focus of the mass transit system, and the fact that a number of consumers are 
attracted by the traditional shopping environment of the downtown area. Some C.B.D.s in other parts of the United States are losing their single locational convenience advantage as many offices are now locating in the suburbs. The factors of center size and distance are apparently still important. The three largest regional centers in the Portland area are also the three centers where most consumers primarily shop. This supports the concept that center size and selection are interrelated, and important in estimating a center's trade area.

The factor of distance is important as consumers will shop the closest available center which is also attractive to them. Both Washington Square and Lloyd Center are comparable centers in terms of their attractiveness, with each enjoying large trade areas. The importance of distance with second choice centers in this study indicates the trade-off of distance with center attractiveness. The greater the distance differential between two competing centers, the greater the influence of distance over the relative attractiveness of a center. But as the distance differential of two centers from the point of origin of the consumer decreases, the relative attractiveness differential becomes more important, as the consumer will travel the extra distance to the more attractive center.

This phenomenon supports the arguments for the spatial choice model espoused by Burnett and others (Burnett, 1973, Ewing, 1974.). The attractiveness of a center and its ability to draw consumers must be viewed with respect to its location relative to other centers.

When estimating the trade area of a center through the use of a gravity model, the spatial choice model, or by some other method, the relative attractiveness of the center must be determined and utilized. 
As this study shows, with regard to the regional shopping centers of Portland, the decisions of a consumer to patronize a particular center is a function of the center's perceived quality of service, its physical character, and its ability to provide a comfortable shopping environment. Consequently, these components comprise the attractiveness and the image of a center. Also important are the size of the center and distance from the consumer's point of origin, traditional components of the gravity model, and the distance to the closest comparable center, the component distinguishing the spatial choice model from the gravity model.

The examination of variations between income groups proves that the upper income consumers shop more frequently at regional shopping centers, and that the upper and middle income consumer are the major patrons of these centers. The upper income groups are characterized by a greater demand for shopping goods with the ability to afford the purchase of high order goods, thus explaining the variations between income groups. These shopping patterns support past theories pertaining to the variations in the patterns of income groups.

Due to problems characteristic of samples utilizing colleges, variations between income groups and the number of centers utilized could not be discerned. The low income group is comprised of students rather than low income families, so in this respect the sample is not representative of a general population.

Variations between male and female shoppers indicates that the female consumer utilizes more regional shopping centers than the male shoppers. With respect to the frequency of shopping, the greatest amount of variation is found among the upper income group, that group 
shopping more frequently at these centers, while the differences among the lower income groups are minimal. This pattern does support the hypothesis that female shoppers would shop more frequently because they are generally the purchasers in family situations.

Few, if any, geographical studies have ever examined variations in the shopping patterns of male and female consumers. This study does indicate that differences do exist, particularly with regard to upper income male and female shoppers. However, because of the problem of sampling college classes, the reliability of these conclusions are suspect to some degree, particularly with regard to the Iower income groups, both of which are composed of male and female respondents. But variations between male and female consumers are indicated and further research is required before any definite conclusions can be reached and the reasons behind these differences, if any, can be isolated.

Further research is also required with respect to the specialty. shopping centers just now beginning to develop in urban areas throughout the United States, as to their influence on surrounding land use, the type of consumers shopping at these centers, and the image of these centers. Research similar to that conducted here could be implemented to discern the attractiveness of community and neighborhood shopping centers and to see if there are variations between high order and low order centers. Finally, the components derived from this study should be utilized in gravity and spatial choice models to increase the level of their predictability and to better explain the existence shopping patterns in the urban environment. 
Ambrose, P.J., 1968, "An Analysis of Intra-Urban Shopping Patterns", Town Planning Review, vol. 38, pp. 327-334.

Applebaum, William and Saul Cohen, 1961, "The Dynamics of Store Trading Areas and Market Equilibrium", Annals of the Association of American Geographers, vol. 51, pp. 73-101.

Applebaum, William, 1968, Store Location Strategy Cases, (Addison-Wesley Publishing Co., Reading, Mass.), p. 164 .

Applebaum, William, et. aI., 1968, Guide To Store Location Research, (Addison-Wesley Publishing Co., Reading, Mass.), p. 259.

Berry, B.J.L. and Wi11iam Garrison, 1958(a), "Recent Developments of Central Place Theory", Papers and Proceedings, Regional Science Association, vol. 4, pp. 107-120.

Berry, B.J.L. and William Garrison, 1958(b), "A Note on Central Place Theory and the Range of A Good", Economic Geography, vo1. 34, pp. 304-311.

Berry, B.J.L., H.G. Barnum and R.J. Tennant, 1962, "Retai1 Location and Consumer Behavior", Papers and Proceedings of the Regiona1 Science Association, no. 9, pp. 65-106.

Berry, B.J.L., 1963, Commercial Structure and Commercial Blight, (The University of Chicago, Dept. of Geography), no. 85, p. 235.

Berry, B.J.L., 1967, Geography of Market Centers and Retail Distribution, Foundations of Economic Geography Series, (PrenticeHal1, Inc., Englewoods Cliffs, New Jersey), p. 146.

Berry, L.L., 1969, "The Components of Department Store Image: A Theoretical and Empirical Analysis", Journal of Retailing, vol. 45, no. 1, Spring 1969, pp. 3-20.

Bruner, James A. and John L. Mason, 1968, "The Influence of Driving Time Upon Shopping Center Preference", Journal of Marketing, vol. 32 , p. 57-61.

Bucklin, Louis P., 1967 (a), "The Concept of Mass in Intra-Urban Shopping", Journal of Marketing, vol. 31, pp. 37-42.

Bucklin, Louis P., 1967 (b), Shopping Patterns in Urban Areas, (Iber Publications, Institute of Business and Economic Research, Research Program in Marketing, Graduate School of Business, University of California, Berkeley), p. 151. 
SELECTED REFERENCES

Bucklin, Louis P., 1971(a), "Trade Area Boundaries: Some Issues in Theory and Methodology", Journal of Marketing Research, vol. 8, pp. 30-37.

Bucklin, Louis P., 1971(b), "Retail Gravity Models and Consumer Choice: A Theoretical and Empirical Critique", Economic Geography, vo1. 47 pp.489-497.

Bucklin, Louis P., 1972, Competition and Evolution in the Distributive Trades, (Prentice-Hall, Inc., Englewoods Cliffs, New Jersey), p.368.

Burnett, Pat, 1973, "The Dimensions of Alternatives in Spatial Choice Processes", Geographical Analysis, vol. 5, pp. 181-204.

Cadwallader, Martin, 1975, "A Behavioral Model of Consumer Spatial Decision-Making", Economic Geography, vol. 51, pp. 339-349.

Casparis, John, 1967, "Metropolitan Retail Structure and Its Relation to Population", Land Economics, vo1. 43, pp. 212-218.

Casparis, John 1969, "Shopping Center Location and Retail Store Mix in Metropolitan Areas", Demography, vol. 6, pp. 125-131.

Catte11, R.B., 1952, Factor Analysis: An Introduction and Manual for the Psychologist and Social Scientist, (Harper and Row, New York, N.Y.), P. 462.

Chapin, F. Stuart Jr., 1968, "Activity Systems and Urban Structure: A Working Scema", American Institute of Planners Journal, vo1. 34, pp.11-18.

Christaller, Waltex, 1966, Central Places in Southern Germany, Trans. by Carlisle W. Baskin, (Prentice-Hall, Englewoods Cliff's, New Jersey), p. 230.

Clark, W.A.V., 1968, "Consumer Travel Patterns and the Concept of Range", Annals of the Association of American Geographers, vol. $58, \mathrm{pp} .386-396$.

Clark, W.A.V. and Gerard Rushton, 1970, "Models of Intra-Urban Consumer Behavior and Their Implications for Central Place Theory", Economic Geography, vol. 46, pp. 486-497.

Clark, W.A.V., 1972, "Behavior and the Constraints of Spatial Structure", New Zealand Geographer, vol. 28, no. 2, pp. 171-180. 
Cohen, Saul B. and George K. Lewis, 1967, "Form and Function in the Geography of Retailing", Economic Geography, vol. 43, pp. 1-42.

Cohen, Yehoshua, 1972, Diffusion of an Innovation in an Urban System, (The University of Chicago, Dept. of Geography) no. 140, p. 136.

Cox, Keith K. and James E. Stafford, 1972, "Negro Retail Shopping and Credit Behavior", Journal of Retailing, vol. 48, pp. 54-66.

Cox, William E. Jr. and Ernest F. Cooke, 1970, "Other Dimensions Involved in Shopping Center Preferences", Journal of Marketing, vol. 34, p. 12-17.

Curry, Leslie, 1967, "Central Places in the Random Spatial Economy", Journal of Regional Science, vo1. 7, supplement, pp. 217-237.

Dacey, M.F., 1965, "The Geometry of Central Place Theory", Geografiska Annaler, vo1. 47B, pp. 111-124.

Davies, Ross L., 1969, "Effects of Consumer Income Differences on Shopping Movement Behavior, Tijdschrift voor Economische en Social Geografie, vol. 60, no. 1, Pp. 112-121.

Davies, R.L., 1972, "Structural Models of Retail Distribution", Institute of British Geographers, Transactions no. 57, pp. 59-82.

Day, R.A., 1973, "Consumer Shopping Behavior in a Planned Urban Environment", Tijidschrift voor Economische en Social Geografie, vo1. $64, \mathrm{pp} .77-85$.

Downs, Roger, 1970, "The Cognitive Structure of an Urban Shopping Center", Environment and Behavior, vo1. 2, no. 1, pp. 13-39.

Enge1, James F., David T. Kollat and Roger D. Blackwe11, 1973, Consumer Behavior, (Holt, Rinehart and Winston Inc., New York, N.Y.), p. 689 .

Ewing, Gary 0., 1974, "Gravity and Linear Regression Models of Spatial Interaction: A Cautionary Note", Economic Geography, vol. 50, pp. 83-88.

Friedly, Philip, 1965, "A Note on the Retail Trade Multiplier and Residential Mobility", Journal of Regional Science, vo1. 6, $57-62$.

Garner, Bárry J., 1966, "The Internal Structure of Retail Nucleations," (Dept. of Geography, Northwestern University, Evanston, I11inois), Studies in Geography, no. 12, p. 183. 


\section{SELECTED REFERENCES}

Getis, Arthur, 1963, "The Determinants of the Location of Retail Activities with Use of a Map Transformation", Economic Geography, vol. 39, pp. 14-22.

Golledge, R.G., 1967, "Conceptualizing the Market Decision Process", Journal of Regional Science, vol. 7, (Supplement) pp. 239-258.

Golledge, R.G. and Lawrence A. Brown, 1967, "Search, Learning, and the Market Decision Process", Geografiska Annaler, vo1. 49, pp. 116-124.

Golledge, R.G., 1969, "The Geographic Relevance of Some Learning Theories", Behavioral Problems in Geography, eds. Kevin Cox and

R.G. Golledge, (Evanston, Illinois, Northwestern University) Studies in Geography, vo1. 17, pp. 101-145.

Golledge, R.G., R. Briggs and D. Demko, 1969, "The Configuration of Distance in Intra-Urban Space", Proceedings of the AAG, vol. 1, pp. 60-65.

Golledge, R.G., 1970, "Some Equilibrium Models of Consumer Behavior", Economic Geography, vo1. 46, (Supplement), pp. 417-423.

Golledge, R.G. and G. Rushton, 1972, Multidimensional Scaling: Review and Geographical Applications, Commission on College Geography, Technical Paper no. 19, Association of American Geographers.

Green, Paul, 1970, "Measurement and Data Analysis", Journal of Marketing, vol. 34, no. 1, pp. 15-17.

Guest, Avery. M., 1973, "Urban Growth and Population Densities", Demography, vol. 10, pp. 450-467.

Guest, Avery M. and C. Cluett, 1973, "Metropolitan Retail Nucleation", Demography, vol. 10, pp. 493-507.

Hilliard, Jimmy E., Ronald L. Vaughn and Fred D. Reynolds, 1975, "A Generalized Utility Model of Shopping Behavior", Advances in Consumer Research, ed. Mary Jane Schlinger, Proceedings of the Annual Conference, Association for Consumer Research, (University of Illinois at Chicago Circle), vol. 2, pp. 157-164.

Holly, Brian P. and James 0. Wheeler, 1972, "Patterns of Retail Location and the Shopping Trips of Low-Income Households", Urban Studies, vol. 9, pp. 215-220.

Horton, Frank E., 1968, "Location Factors as Determinants of Consumer Attraction to Retail Firms", Annals of the Association of American Geographers, vol. 58, pp. 787-801. 
Horton, Frank E., 1969, "An Investigation of Individual Action Spaces: A Progress Report", Proceedings of the AAG, vol. 1, pp. 70-75.

Horton, Frank E. and William E. Wagner, 1969, "A Markovian Analysis of Urban Travel Behavior: Pattern Response by Socioeconomic-Occupation Groups", Highway Research Record, vo1. 183, pp. 19-29.

Horton, Frank E. and David R. Reynolds, 1971, "Effects of Urban Spatial Structure on Individual Behavior", Economic Geography, vo1. 47; pp. 35-47.

Horton, Frank E. and David R. Reynolds, 1975, "Action Space Information: A Behavioral Approach to Predicting Urban Travel Behavior", Advances in Consumer Research, ed. Mary Jane Schlinger, vo1. 2, PP. 136-148.

Hudson, Ray, 1975, "Patterns of Spatial Search", Institute of British Geographers, Transactions, 65, pp. 14I-154.

Huff, David, 1959 (a), "Geographical Aspects of Consumer Behavior", University of Washington, Business Review, vol. 18, pp. 27-38.

Huff, David, 1959 (b), A Topological Model of Consumer Space Preferences, (Bureau of Business Administration, University of Washington, Seattle, Washington), Occasiona1 Paper no. 11, p. 25.

Huff, David, 1962, Determination of Intra-Urban Retail Trade Areas, (Real Estate Research Program, Graduate School of Business Administration, Division of Research, University of California, Los Angeles), p. 47 .

Huff, David and Richard R. Batse11, 1975, "A Conceptua1 and Operational Problem with Market Share Models of Consumer Spatial Behavior", Advances in Consumer Research, ed. Mary Jane Schlinger, vol. 2, pp. 165-172.

Isard, Walter, 1960, Methods of Regional Analysis, (The M.I.T. Press, Cambridge, Mass.), p. 784 .

Isard, Walter, 1965, Location and Space Economy, (Cambridge, M.I.T. Press), p. 350 .

Isard, Walter, 1975, "A Simple Rationale for Gravity Mode1 Type Behavior", Papers Regional Science Association, vo1. 35, pp. 25-30.

James, Derreand and Drives, 1976, "The Use of Multi-Attribute Models in a Store Image Study", Journal of Retailing, vol. 52, no. 2, p. 24-32. 
Jolson, Marvin E. and Walter F. Spath, 1973, "Understanding and Fulfilling Shopper's Requirements: An Anomaly in Retailing", Journal of Retailing, vol. 49, pp. 38-50.

Jonassen, C.T., 1955, Shopping Center Versus Downtown, (Bureau of Business Research, College of Commerce and Administration, The Ohio State University, Columbus, Ohio), p. 170.

Kelley, R.F. and R. Stephenson, 1967, "The Semantic Differentia1: An Information Source for Designing Retail Patronage Appeals", Journal of Marketing, vol. 31, pp. 43-47.

King, L.J., 1969, Statistical Analysis in Geography, (Prentice-Ha11, Englewoods Cliff, N.J.), p. 28.8 .

Kunke1, J.H. and L.L. Berry, 1968, "A Behavioral Conception of Retail Image", Journal of Marketing, vol. 32, no. 4, pp. 21-17.

Lakshmanan, T.R. and W.G. Hansen, 1965, "A Retail Market Potential Mode1", Journal of the American Institute of Planners, vo1. 31, pp. $134-143$.

Lathrop, George T., 1971, "Characteristics of Urban Activity Patterns", Highway Research Record, vol. 322, pp. 232-244.

Lazer, William and Robert G. Wyckham, 1969, "Perceptual Segmentation of Department Store Markets", Journal of Retailing, vol. 45, pp. 325.

Lee, C., 1973, Models in Planning, (Pergamon Press, Oxford, New York), p. 142 .

Lindquist, Jay D., 1974-75, "Meaning of Image", Journal of Retailing, vol. 50, pp. 29-39.

McDouga1, G.H.G. and J.N. Fry, 1974-75, "Combining. Two Methods of Image Measurement", Journal of Retailing, vol. 50, no. 4, pp. 53-61.

Marble, Duane F., 1959, "Transport Inputs at Urban Residential Sites", Papers and Proceedings of the Regional Science Association, vol. 5, pp.253-266.

Mason, Joseph Barry and Charles Thomas Moore, 1970-71, "An Empirica1 Reappraisal of Behavioristic Assumptions in Trading Area Studies", Journal of Retailing, vol. 48, pp. 31-37.

Messick, S.J., 1969, "Metric Properties of the Semantic Differential", Semantic Differential Technique, ed. James G. Snider and Charles E. Osgood, (Aldine Pub. Co. Chicago), pp. 161-168. 
Mindak, W.A., 1961, "Fitting the Semantic Differential to Marketing Problems", Journal of Marketing, vol. 25, pp. 69-72.

Mulvihi11, Donald F. and Ruth Cope Mulvihi11, 1970, Geography, Marketing, and Urban Growth, (Van Nostrand Reinhold Co., New York, N.Y.), Pp. 189 .

Murdie, Robert A., 1965, "Cultural Differences in Consumer Travel", Economic Geography, vol. 41, pp. 211-233.

Myers, James H., Roger R. Staton and Arne F. Hayes, 1971, "Correlates of Buying Behavior: Social Class vs. Income", Journal of Marketing, vol. 35, pp. 8-15.

Nader, G.A. and D. Thorpe, 1967, "Customer Movement and Shopping Center Structure: A Study of a Central Place System in Northern Durham", Regional Studies, vol. 1, pp. 173-191.

Nader, G.A., 1969, "Socio-Economic Status and Consumer Behavior", Urban Studies, vol. 16, pp. 235-245.

Neidercorn, J.H. and B.V. Becholdt Jr., 1969, "An Economic Derivation of the "Gravity Law" of Spatial Interaction", Journal of Regional Science, vol. 19, pp. 30-37.

Nystuen, John D., 1967, "A Theory and Simulation of Intra-Urban Trave1", Quantitative Geography Part I: Economic and Cultural Topics, eds. W.I. Garrison and D.F. Marble, (Northwestern University, Dept. of Geography, Evanson, Illinois), Studies In Geography, pp. 54-83.

Olsson, Gunnar and Stephen Gale, 1968, "Spatial Theory and Human Behavior", The Regional. Science Association Papers, vol. 21, pp. 229-242.

Usgood, C.E., G.J. Suci and P.H. Tannenbaum, 1957, The Measurement of Meaning, (University of Illinois Press, Urbana), P. 342.

Prasad, V. Kanti, 1972, "Correlates of Multivariate Food Shopping", Journal of Retailing, vol. 48, pp. 74-81.

Pred, Allen, 1967, Behavior and Faundations For A Geographic and Dynamic Location Theory, (Lund Series in Geography, The Royal University of Lund, Sweden, Dept. of Geography), part I, p. 8.

Redstone, L.G., 1973, New Dimensions in Shopping Centers and Stores, (McGraw-Hi11 Inc., New York), p. 322.

Keilly, William, 1931, The Law of Retail Gravitation, (The Knickerbocker Press, New York, N.Y.), p. 210. 


\section{SELECTED REFERENCES}

Rich, Stuart U. and Subhash C. Jain, 1968, "Social Class and Life Cycles as Predictors of Shopping Behavior", Journal of Marketing Research, 5, pp. 41-49.

Rudelius, William, Robert F. Hall and Roger A. Kerin, 1972, "Assessing Retail Opportunities in Low Income Areas", Journal of Retailing, vo1. 48, pp. 96-114.

Rumme1, R.J., 1967, "Understanding Factor Analysis", Journal of Conflict Resolution, vol. 11, no.4, pp. 444-479.

Rummel, R.J., 1970, Applied Factor Analysis, (Northwestern University, Evanston), p. 617 .

Rushton, Gerard, 1969(a), "Analysis of Spatial Behavior By Revealed Space Preference", Annals of the Association of American Geographers, vo1. 59, pp. 391-400.

Scott, Peter, 1970, Geography and Retailing, (Hutchinson University Libraxy, London), p. 182 .

Sexton, Donald E. Jr., 1972, "Black Buyer Behavior", Journal of Marketing, vo1. 36, pp. 36-39.

Sherman Edith N. and Margaret. R. Britton, 1973, "Contemporary Food Gatherers: A Study of Shopping Habits of an Elderly Urban Population", Gerontologist, vol. 13, pp. 358-364.

Simmons, James, 1964, The Changing Pattern of Retail Location, (The University of Chicago, Dept. of Geography, Chicago, I11inois), vo1. 92, p. 200.

Simons, Peter, 1973-74, "Shape of Retail Market Areas: Implications from a literature Review", Journal of Retailing, vol. 49, pp. 65-78.

Singson, Ricardo L., 1975, "Multidimensional Scaling Analysis of Store Image and Shopping Behavior", Journal of Retailing, vol. 51, pp. 38-52.

Smith, Tony E., 1975, "An Axiomatic Theory of Spatial Discounting Behavior", Papers Regional Science Association, vol. 35, pp. 31-44.

Stea, David and Roger Downs, 1970, "From the Outside Looking In at the Inside Looking Out", Environment and Behavior, vo1. 2, pp. 3-11.

Suttles, Gerald D., 1970, The Social Order of the Slum, (The University of Chicago Press, Chicago, I1linois), p. 234. 
Thompson, Donald L., 1966, "Future Direction in Retail Area Research", Economic Geography, vol. $42 ;$ pp. 1-18.

Thompson, Bryan, 1967, "An Analysis of Supermarket Shopping Habits in Worcester, Massachusetts", Journal of Retailing, vol. 43, pp. 17-29.

Thompson, Bryan, 1969, "Intraurban Retail Structure: The Supermarket Sector", Journal of Retailing, vo1. 45, pp. 69-80.

Thorpe, D. and G.A. Nader, 1967, "Customer Movement and Shopping Centre Structure: A Study of a Central Place System in Northern Durham", Regional Studies, vol. 1, pp. 171-191.

Vance, James E. Jr., 1962, "Emerging Patterns of Commerical Structure in American Cities", The IGU Symposium in Urban Geography, The Royal University of Lund, Dept. of Geography, (C.W.K. Glerup Publishers of Lund), pp. 485-519.

Wagner, William, 1974, "An Empirical Test of Reilly's Law of Retail Gravitation", Growth and Change: A Journal of Regional Development, vo1. 5, pp. 30-36.

Warx, P. and C. Knapper, 1968, The Perception of People and Events, (John Wiley \& Sons, London), p. 485.

Warwick, D.P. and C.A. Liniger, 1975, The Sample Survey: Theory and Practice, (McGraw-Hil1 Book Co.), p. 344 .

Wolpert, Julian, 1964, "The Decision Process in Spatial Context", Annals of the Association of American Geographers, vol. 54, pp. 537-558.

Yeates, M., 1974, An Introduction to Quantitative Analysis in Human Geography, (McGraw-Hil1 Book Co., New York), p. 300.

Yuil1, Robert S., 1967, "Spatial Behavior of Retail Customers: Some Empirical Measurements", Geografiska Annaler, 49b, pp. 105-115. 
APPENDIX A

DEMOGRAPHIC AND SOCIO-ECONOMIC CHARACTERISTICS

OF THE SANDIE POPULATION

\begin{tabular}{lrrr} 
Sex & Freguency & $\begin{array}{c}\text { Relative } \\
\text { Percent }\end{array}$ & $\begin{array}{c}\text { Cumulative } \\
\text { Percent }\end{array}$ \\
& 154 & $51.3 \%$ & $51.3 \%$ \\
Female & 146 & $48.7 \%$ & $100.0 \%$ \\
Age & & & \\
\hline $10-24$ & 97 & $32.3 \%$ & \\
$25-29$ & 65 & $21.7 \%$ & $32.3 \%$ \\
$30-39$ & 70 & $23.3 \%$ & $54.0 \%$ \\
$40-49$ & 36 & $12.0 \%$ & $77.3 \%$ \\
$50-59$ & 26 & $8.7 \%$ & $89.3 \%$ \\
$60+$ & 5 & $2.0 \%$ & $98.0 \%$
\end{tabular}

Education

College Plus

23

$7.7 \%$

$7.7 \%$

College Grad.

$11.7 \%$

$19.4 \%$

some College

$56.7 \%$

$76.1 \%$

High school.

Graduate

58

$9.3 \%$

$95.4 \%$

Less Than

12 Years

14

$4.6 \%$

$100.0 \%$

Marital Status

$\begin{array}{lll}\text { Married. . . . . } & 57\end{array}$

$52.3 \% \quad 52.3 \%$

single

.43

47.7 웅

$100.0 \%$ 
APPENDIX A (continued)

Number of Children

No Chilaren

$1-2$

$3-4$

5-7

8. Plus

\section{Income}

0-\$999

$\$ 1,000-\$ 4,999$

$\$ 5,000-\$ 9,999$

$\$ 10,000-\$ 14,999$

\$15,000-\$24,999

$\$ 25,000$ Plus

\section{Occupation}

Professional \&

Technical

Managers \&

Administrátors

Sales Workers

clerical \& Kindred workers

Craftsmen, Foremen \&

Kindred Workers

21

56

53

64

69

37

12.

2

46

2

54

28

21

40

11
Cumulative

Percent.

$$
49.38
$$

$30.7 \%$

$15.3 \%$

$4.0 \%$

.78

$49.3 \%$

$80.0 \%$

$95.3 \%$

$99.3 \%$

$100.0 \%$

Unskilled Labor . 13

Operatives

$7.0 \%$

$7.0 \%$

$18.7 \%$

25.7 웅

$17.7 \%$

$43.3 \%$

$21.3 \%$

$64.7 \%$

$23.0 \%$

$87.7 \%$

$12.3 \%$

$100.0 \%$

$18.0 \%$

$18.0 \%$

9.38

$27.3 \%$

$7.0 \%$

$34.3 \%$

$13.3 \%$

$47: 6 \%$

$3.7 \%$

$51.3 \%$

13

$4.3 \%$

55.6 둥

6

2.08

$57.6 \%$

Service Workers

$8.7 \%$

$66.3 \%$

students

26

$21.7 \%$

$88.0 \%$

other

65

$12.0 \%$

$100.0 \%$ 
The purpose of this questionnaire is to find and describe those features of a shopping center, such as Lloyd Center, or of a shopping area, such as Downtown Portland, that affect your decision to shop in a particular shopping center or area. However, this decision should center around a shopping trip to purchase those goods which you usually shop for in shopping centers or areas such as Washington Square, Lloyd Center, Downtown Portland, Old Town, Jantzen Beach, and John's Landing. These shopping centers and areas are referred to as regional shopping centers in that they are large in terms of the numbers of shops and the wide variety of goods that are offered, the availability of parking, and their ability to attract customers from a large area. Therefore, throughout the questionnaire the shopping centers and areas listed above shall be referred to as the regional shopping centers of the Portland area. Card 1 lists these regional shopping centers and it may be referred to throughout the questionnaire. Each question should be answered in reference to a shopping trip to one of Portland's regional shopping centers.

In the first part of the questionnaire you will be offered a seven point scale following each question on which you can express the importance, meaning, or description of that thing being asked in the question. On the end of each scale there will be a word or phrase which is the opposite in meaning of the word or phrase on the other end of the scale. For example,

$\begin{array}{ll}\text { Good } & \text { Bad } \\ \text { Important } & \text { Unimportant } \\ \text { Fast } & \text { Slow } \\ \text { Attractive } & \text { Unattractive }\end{array}$

Each point along the scale offers you the opportunity to express the importance, meaning, or description of that thing being asked in the question, such that you are offered,

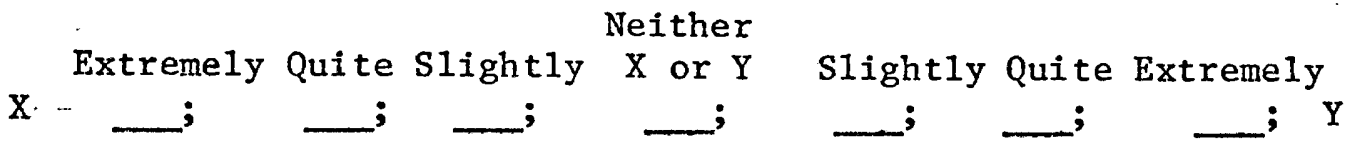

You would then select, the appropriate space to mark: For example, if you were asked the importance of something in your decision to shop at a particular regional shopping center in the Portland area and it is quite important in your decision, then you would mark

Important __; $\mathrm{X}_{-}$_ _ _ _ _ _ _ _ _ _ _ Unimportant 
Or if it is extremely umimportant to you when you make your decision, then you would mark

Important

But if it were neither important or unimportant, that is you did not even consider it when making your decision as to where to shop, you would then mark

Important

The same holds true when you are asked to describe the characteristics of something that is important to your decision as to where to shop. For example, you are asked to describe the characteristics of service that is important in your decision to shop at a particular regional shopping center and one of the characteristics listed is Fast Slow. If slightly fast is descriptive of the importance of that characteristic of service In your decision, you would then mark

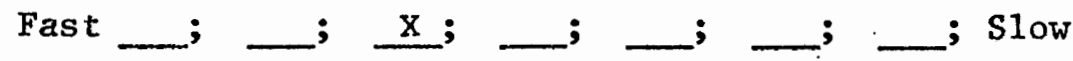

Or if you liked service that was slightly slow while you are shopping in one of Portland's regional shopping centers, you would mark

Fast

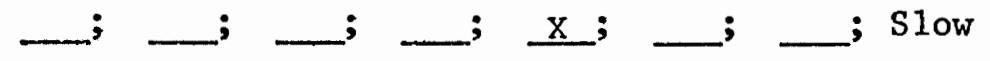

Or if this particular characteristic of service is not important or it plays no part in your decision, you would mark

Fast
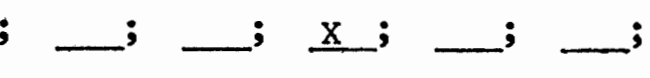
; Slow

Please answer each of the questions as instructed in the questionnaire.

Your participation is very important to the success of the study and it is greatly appreciated. 
1) How important are the prices of goods in your decision to shop at one of Portland's regional shopping centers? Mark the appropriate space.

Important __; __; _ _ _ _ _ _ _ _ _ _ Unimportant

2) What characteristics of price are important to you in your decision to shop at one of Portland's regional shopping centers?

Good Values for

the Money
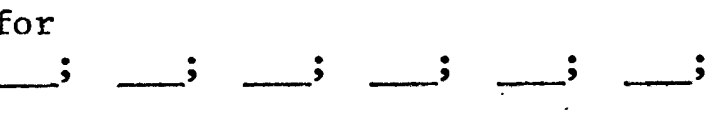

Poor Values

Not:

Competitive

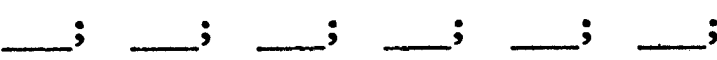

; __ Competitive

Many Sales

;

; _ _ _ _ ;

; Few Sales

3) Describe the selection of goods important to you in choosing a regional shopping center at which to shop.

Narrow

Broad

Selection

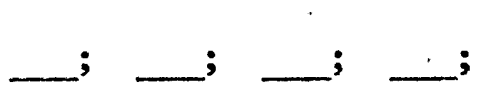

$\longrightarrow$

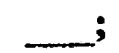

;

; Selection

Can get

the Good

4) How important is service in your decision to shop at one of

Portiand's regional shopping centers?

Important
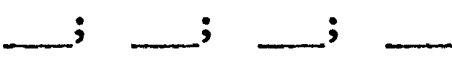

;

;

; Unimportant

5) Describe those characteristics of service that are important to you in your decision to shop at one of Portland's regional shopping centers. Mark the appropriate space.

Fast
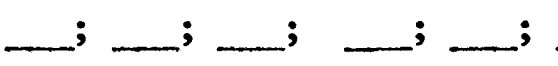

;

; Slow

Rude

Employees
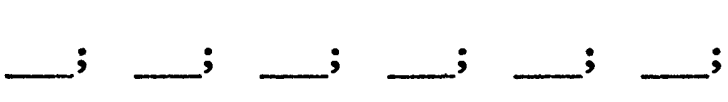

Polite

Helpful
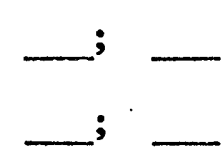

Warm
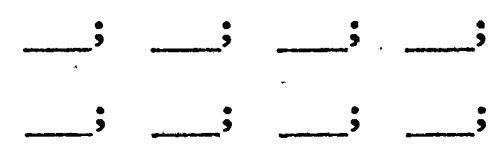

_; Unhelpful

Know led ge ab le

About the

Good 
6) How important is the ability to move with ease in one of Portland's regional shopping centers, in your decision to shop at one of them?

Important

7) To you,. what conditions best describe the east of movement within one of the regional shopping centers of Portland?

Many

Shoppers

Wide

Pavements

Have to

Cross

Streets

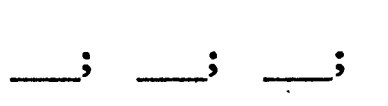

Few

; Shopppers

Narrow

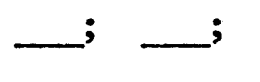

Pavements

Do not have to

Easy to Move

From Shop

to Shop

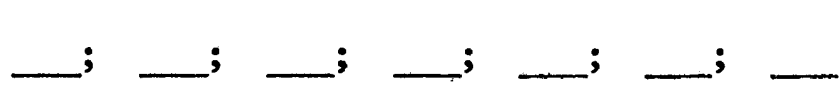

; Cross Streets

Difficult to Move From Shop to Shop

8) Of those physical conditions described below, mark the space which most closely reflects how you feel about them in relation to a regional shopping center in which to shop.

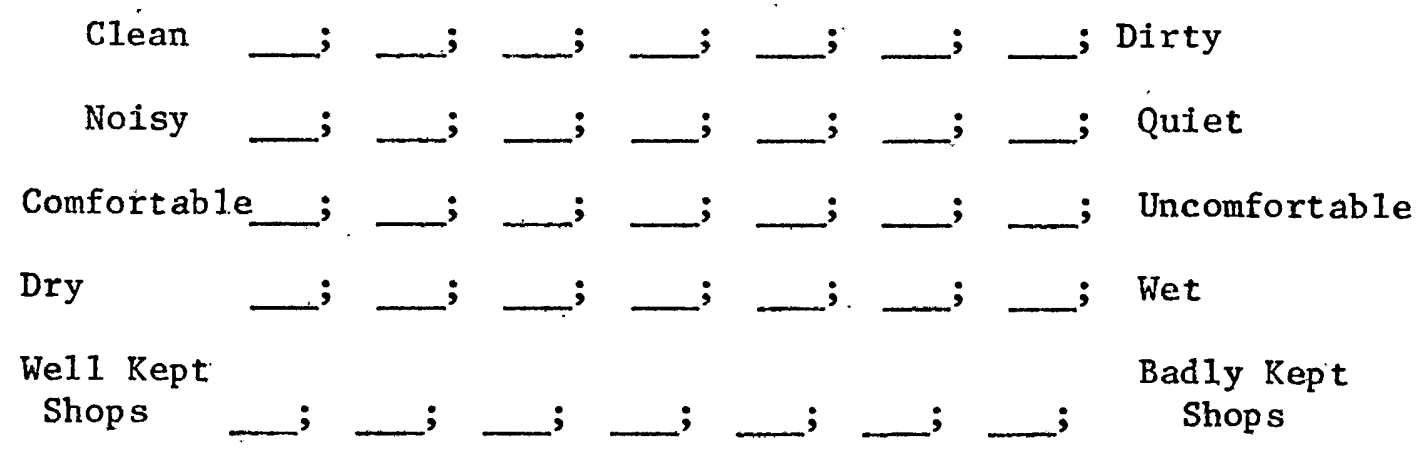

9) Which of the following shopping hours appeals to you in your decision to shop at one of Portland's regional shopping center?

9am 6pm everyday ___;

9am 9pm everyday

9am 9pm two days a week and 9am $6 \mathrm{pm}$ the rest of the week 


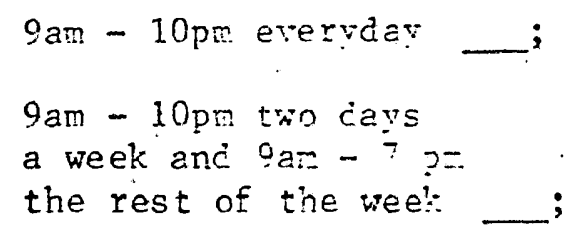

10) How important are the shopping hours of a regional shopping center in your decision to shop at one of them?

Important

11) Describe those physical characteristics of a regional shopping center which appeal to you in your decision to shop at one of Portland's regional shopping centers. Mark the space which best describes those physical characteristics listed below which appeal to you.

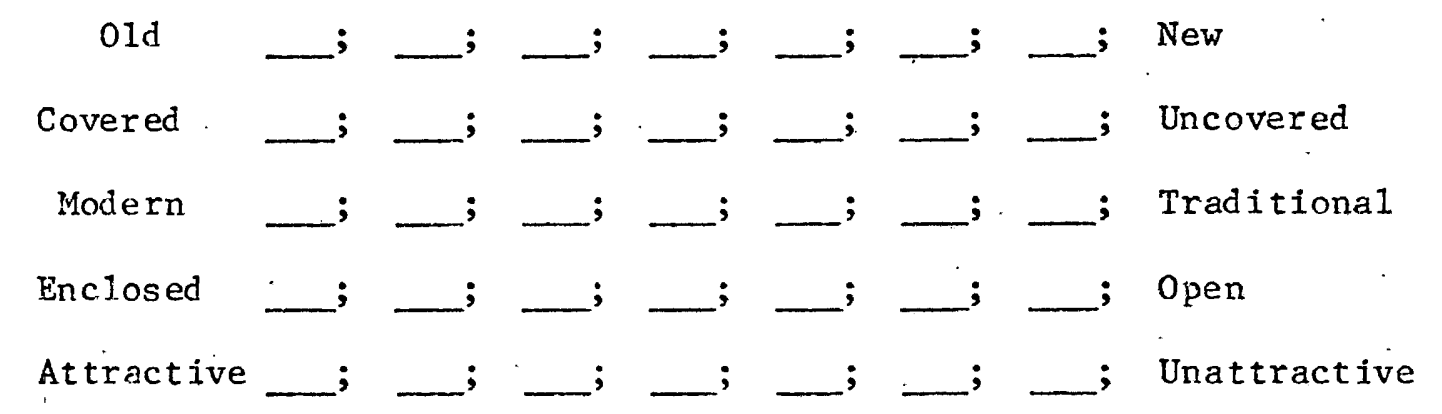

12) How important are the physical characteristics of a regional shopping center in your decision to sho? at one in Portland?

Important

13) Which of the following characteristics best describes that regional shopping center in which you do a zeiority of your shopping?

Many

Shoppers

Open

Mass Transit

Readily

Available

Fast

Service

Traditional

Des $i g n$
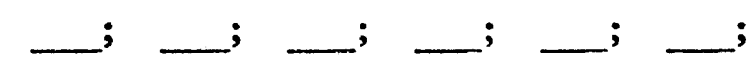

; Unimportant 
Short Travel

Time to

the Center

Polite

Employees

Competitive

Prices

Easy

Parking

Poor Values

for the

Money

Broad

Selection of Goods
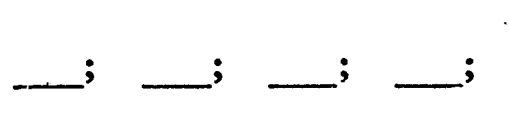

Long Trave1

Time to

the Center

Rude

Employees

Uncompetitive

Prices

\section{Difficult}

Parking

Good Values

for the

Money

Narrow

Selection

of Goods

\section{1d}
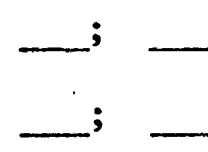

-

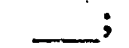

$\ldots$

-

; New

14) What is the importance of the amount of time that it takes you to travel to one of Portland's regional shopping centers?

Important

15) How much time does it take you to travel to that regional shopping center you most frequently visit? Sark the appropriate space.

0-4 min. 5-9 min. 10-14 min. 15-24 min. $25-34$ min. $35-44$ min. $45+\min$.

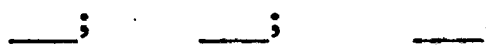

16) How frequently do you shop at one of Portland's regional shopping centers?

More than

Once

Once a Month Once a Month than 4 times a yr. times a year Never

$\begin{array}{ll}\text { a Nonth but nore } & \text { Less than } 4 \\ \text { than } 4 \text { times a yr. times a year Never }\end{array}$

$-$
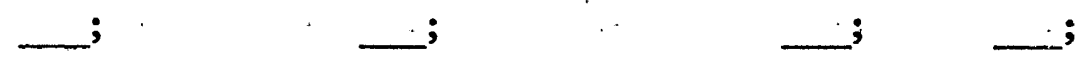

(If you marked Never to question 16 , then skip to question 24 and proceed from there.)

17) From what point do you usually begin your shopping trip to one of Portland's regional shopping centers?

Home ; Work Other (Please specify) 
18) What form of transportation do you usually use to shop at one of Portland's regional shopping centers?

Car ___; Bus ___ Walk ___ Bicycle ___; Other (specify)

19) How important is the ease of parking in your decision to shop at one of the regional shopping centers of Portland?

Important __; __ _ _ _ _ _ _ _ _ _ _ _ Unimportant

20) Do you ever travel to one of Portland's regional shopping centers for any other reason other than to shop?

No ___ Y Yes ___ If you answered yes, please specify the other reasons or reason and the center you visited. Refer to Card 1.

21) What percent of your shopping trips to Portland's regional shopping centers are associated with each of the centers listed on Card 1 and below. For example, if you shop at Lloyd Center $50 \%$ of the time, at Jantzen Beach $30 \%$ of the time, and at John's Landing $20 \%$ of the time, you would attach the appropriate percentage figure to the centers listed below. (IMPORTANT, the percentage figures should add up to $100 \%$ ).

Washington Square $\%$ \% $\%$
Lloyd Center
Downtown Portland $\%$ \% $\%$
Old Town
Jantzen Beach
John's Landing

22) When you shop at one of Portland's regional shopping center, during what part of the week do you usually shop?

Weekends ___ Weekdays ___ ; 
23) During what part of the day do you usually shop at one of the regional shopping centers of Portland?

$$
\text { Morning ___ Afternoon ___; Evenings __; }
$$

24) How long have you lived at your present address? (Years and/or months). (If you have lived at your present address for more than one year, then skip question 25 and proceed with question 26).

25) If you have lived at your present address for less than one year, then was your prior address in the Portland area?

$$
\text { Yes___ No ___ } \quad \begin{aligned}
& \text { (If you answered No, where were you } \\
& \text { living before? The city, county, } \\
& \text { state, or country). }
\end{aligned}
$$

26) What is your present address?

(This is strictly confidential)

27) What is your zip code?

28) What is your age?

29) What is your sex? Male __; Female _ _

30) How many years of school have you completed?

31) What is your occupaton?

32) What is your marital status? Married

Single

33) Do you have any children?

No ___ Y Y _ _ _ (If you answered YES, then how many children do you have? 
APPENDIX B (continued)

34) Approximately what is your yearly income? (If you are married, then what is the combined income of you and your spouse?) Mark the appropriate space.

$$
\begin{aligned}
& \$ 0-999 \\
& \$ 1,000-4,999 \\
& \$ 5,000-9,999 \\
& \$ 10,000-14,999 \\
& \$ 15,000-24,999 \\
& \$ 25,000+
\end{aligned}
$$

